


\section{Revision of the National Residue Control Plan - Application on the Red Meat Supply Chain}

E.D. van Asselt, M.Y. Noordam, M.G. Pikkemaat, L.A. van Ginkel, S.S. Sterk

This research has been carried out by RIKILT Wageningen University \& Research, institute within the legal entity Wageningen Research Foundation funded by the Dutch Ministry of Agriculture, Nature and Food Quality (WOT-02-002-004).

Wageningen, April 2018

RIKILT report 2018.003 
E.D. van Asselt, M.Y. Noordam, M.G. Pikkemaat, L.A. van Ginkel, S.S. Sterk, 2018. Revision of the National Residue Control Plan - Application on the Red Meat Supply Chain. Wageningen, RIKILT Wageningen University \& Research, RIKILT report 2018.003. 62 pp.; 15 fig.; 10 tab.; 47 ref.

Project number: 1267341102

BAS code: WOT 02-002-004

Project title: Revision of the National Residue Control Plan

Project leader: Esther van Asselt

This report can be downloaded for free at https://doi.org/10.18174/446468 or at www.wur.eu/rikilt (under RIKILT publications).

(C) 2018 RIKILT Wageningen University \& Research, institute within the legal entity Wageningen Research Foundation. Hereinafter referred to as RIKILT.

The client is allowed to publish or distribute the full report to third parties. Without prior written permission from RIKILT it is not allowed to:

a) publish parts of this report;

b) use this report or title of this report in conducting legal procedures, for advertising, acquisition or other commercial purposes;

c) use the name of RIKILT other than as the author of this report.

P.O. Box 230, 6700 AA Wageningen, The Netherlands, T +31 (0)317 4802 56, E info.RIKILT@wur.nl, www.wur.eu/rikilt. RIKILT is part of Wageningen University \& Research.

This report from RIKILT has been produced with the utmost care. However, RIKILT does not accept liability for any claims based on the contents of this report.

RIKILT report 2018.003

Distribution list:

- Marca Schrap, Netherlands Food and Consumer Product Safety Authority (NVWA)

- Rick Herbes, Netherlands Food and Consumer Product Safety Authority (NVWA)

- Antoon Opperhuizen, Netherlands Food and Consumer Product Safety Authority (NVWA) 


\section{Contents}

Summary $\quad 5$

$\begin{array}{ll}\text { Definition of terms and abbreviations } & 7\end{array}$

1

$\begin{array}{ll}\text { Introduction } & 11\end{array}$

2

$\begin{array}{ll}\text { Materials and Methods } & 12\end{array}$

2.1 Scope 12

2.2 Literature review $\quad 12$

2.3 Monitoring data $\quad 12$

2.4 An alternative method of sampling for steroids $\quad 12$

2.5 Theoretical approach to pooling 13

$\begin{array}{lll}2.6 & \text { Laboratory experiments on pooling } & 13\end{array}$

3.1 Background information on the red meat supply chain $\quad 15$

3.1.1 Data on the red meat supply chain $\quad 15$

3.1.2 Overview of the use of veterinary drugs 16

3.1.3 Legal limits applying to the red meat supply chain $\quad 17$

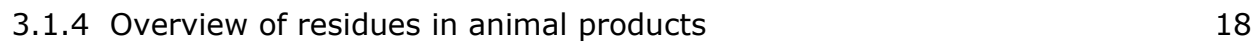

$\begin{array}{ll}3.1 .5 \text { KAP database } & 22\end{array}$

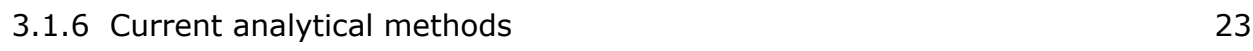

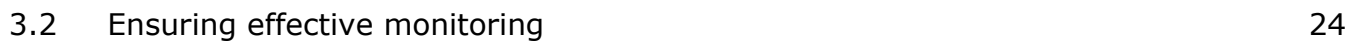

3.2.1 Introduction $\quad 24$

3.2.2 Compiling the list of substances $\quad 25$

$\begin{array}{ll}3.2 .3 \text { Determining the matrix } & 38\end{array}$

3.2.4 The heel prick method for analysing steroid esters 39

$\begin{array}{lll}3.3 & \text { Efficient monitoring } & 41\end{array}$

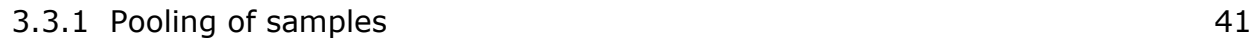

$\begin{array}{ll}\text { 3.3.2 Identification of emerging risks } & 46\end{array}$

$4 \quad$ Conclusions and recommendations $\quad 51$

$\begin{array}{lll}4.1 & \text { Conclusions } & 51\end{array}$

$\begin{array}{lll}4.2 & \text { Recommendations } & 51\end{array}$

$5 \quad$ Acknowledgements $\quad 53$

$\begin{array}{ll}\text { References } & \mathbf{5 4}\end{array}$

Annex $1 \quad$ List of substances in Directive 96/23/EC 57

$\begin{array}{lll}\text { Annex } 2 & \text { Score-based prioritisation } & 58\end{array}$

$\begin{array}{lll}\text { Annex } 3 & \text { Pool experiments } & 60\end{array}$ 



\section{Summary}

The current rules governing official controls on animal production chains are under review and it is likely that monitoring will in future be more risk-based in nature. The purpose of this study was therefore to devise an action plan for a more risk-based implementation of the National Plan (NP) for Residues. 'Risk' in this respect is defined as a combination of the probability that a hazard will occur and its possible health effects (i.e. the severity of the hazard). This study examined the extent to which monitoring can be made more effective and efficient. The red meat supply chain was chosen as a case study.

The study begins by describing the current status of the red meat supply chain and providing an overview of current analytical methods and the results of monitoring. The percentage of non-compliant results for red meat was found to be generally low (about $0.2 \%$ ). The substances detected vary, depending on the animal species.

By developing a risk-based monitoring programme, current monitoring can be made more effective. To that end, three decision trees were created based on literature review and expert knowledge: I. Prohibited substances; II. Contaminants, natural substances and pesticide residues; and III. Substances authorised for veterinary drugs and feed additives. These decision trees can be used to classify substances, per animal species, as having 'high', 'medium' or 'low' priority for inclusion in the NP for Residues. The three decision trees were each tested using a number of substances. The test showed that the method can work well as a means of prioritising substances on the basis of risk (probability of occurrence and the severity of the substance).

Moreover, our study examined whether current monitoring could be made more efficient by pooling samples. Calculations were done on the basis of the current monitoring data and experiments with cattle urine enriched with $\beta$-agonists. Both the calculations and the experiments showed that, for some substances, up to five samples could be pooled, whereas a maximum of two samples could be pooled for substances whose detection limit is close to the legal limit.

The investigation also looked at the identification of emerging risks. An analytical approach to identify emerging risks is possible by using broad screening techniques, which also allow retrospective searches. Furthermore, it is possible to adopt a holistic approach in which software tools and statistical calculations are used to detect factors influencing the emergence of new hazards in the supply chain.

Based on the findings of this study, we drew up an action plan with a view to devising a risk-based monitoring plan, which includes the creation of a team of experts who would prioritise the various substances and groups of substances with the aid of the decision trees, and production and consumption data. Once it is apparent which substances are to be monitored in which types of animal, the most suitable matrix can be selected. This risk-based monitoring plan will need to be updated annually on the basis of acquired (statistical) knowledge and analytical findings. Moreover, some of the monitoring will need to be done on a random basis in order to ensure that hazards are not overlooked. It is recommended that broad screening methods be used, which not only detect prioritised substances but also have a broader focus, so that emerging risks can be identified. 


\section{Definition of terms and abbreviations}

\begin{tabular}{|c|c|c|}
\hline $\begin{array}{l}\text { Term/ } \\
\text { abbreviation }\end{array}$ & Definition & Source \\
\hline $\begin{array}{l}\text { Action limit } \\
\text { (RPA) }\end{array}$ & $\begin{array}{l}\text { The level of a residue of a pharmacologically active } \\
\text { substance established for control reasons in the } \\
\text { case of certain substances for which a maximum } \\
\text { residue limit has not been laid down in accordance } \\
\text { with this Regulation. }\end{array}$ & $\begin{array}{l}\text { Regulation (EC) No } 470 / 2009 \\
\text { (Article } 1(1 . b) \text { ) }\end{array}$ \\
\hline $\mathrm{BN}$ & Bayesian network & \\
\hline $\mathrm{CCa}$ & $\begin{array}{l}\text { Decision limit ( } \mathrm{CCa} \text { ) means the limit at and above } \\
\text { which it can be concluded with an error probability } \\
\text { of a that a sample is non-compliant. }\end{array}$ & $\begin{array}{l}\text { Decision 2002/657/EC (Annex I, } \\
1.11 \text { ) }\end{array}$ \\
\hline $\mathrm{CC} \beta$ & $\begin{array}{l}\text { Detection capability }(C C \beta) \text { means the smallest } \\
\text { content of the substance that may be detected, } \\
\text { identified and/or quantified in a sample with an } \\
\text { error probability of } \beta \text {. In the case of substances for } \\
\text { which no permitted limit has been established, the } \\
\text { detection capability is the lowest concentration at } \\
\text { which a method is able to detect truly } \\
\text { contaminated samples with a statistical certainty } \\
\text { of } 1 \text { - } \beta \text {. In the case of substances with an } \\
\text { established permitted limit, this means that the } \\
\text { detection capability is the concentration at which } \\
\text { the method is able to detect permitted limit } \\
\text { concentrations with a statistical certainty of } 1-\beta \text {. }\end{array}$ & $\begin{array}{l}\text { Decision 2002/657/EC (Annex I, } \\
1.12 \text { ) }\end{array}$ \\
\hline DBS & Dry Blood Spot & \\
\hline DDDA & $\begin{array}{l}\text { Defined Daily Dose Animal: the number of days of } \\
\text { antimicrobial treatment per animal per year. The } \\
\text { DDDA }_{\text {NAT, the national DDDA, is calculated as the }} \\
\text { sum of the treatable kilograms in an animal sector } \\
\text { over a year divided by the average number of } \\
\text { kilograms of animal present in the animal sector. } \\
\text { This measure is used to obtain the usage for each } \\
\text { type of animal at sectoral level, independent of } \\
\text { farm type or category and is also used in other } \\
\text { countries. The measure is similar to the human } \\
\text { measure of DDD per } 1000 \text { person days and is } \\
\text { subject to a conversion factor of } * 1000 / 365 \text {. } \\
\text { The measure is expressed in terms of } \\
\text { DDDA/animal year. }\end{array}$ & (SDA, 2016b) \\
\hline EFSA & European Food Safety Authority & \\
\hline EURL & EU Reference Laboratory & \\
\hline FIDIN & $\begin{array}{l}\text { Association of Netherlands Manufacturers and } \\
\text { Importers of Veterinary Drugs }\end{array}$ & \\
\hline GGD & Municipal Health Services & \\
\hline Hazard & $\begin{array}{l}\text { A biological, chemical or physical agent in, } \\
\text { or condition of, food or feed with the potential to } \\
\text { cause an adverse health effect. }\end{array}$ & $\begin{array}{l}\text { Regulation (EC) No } 178 / 2002 \\
\text { (Article 3(14)) }\end{array}$ \\
\hline KAP & Quality Programme for Agricultural Products & \\
\hline KNMvD & $\begin{array}{l}\text { The Royal Netherlands Association of Veterinarians } \\
\text { (Koninklijke Nederlandse Maatschappij voor } \\
\text { Diergeneeskunde) }\end{array}$ & https://www.knmvd.nl/ \\
\hline
\end{tabular}




\begin{tabular}{|c|c|c|}
\hline $\begin{array}{l}\text { Term/ } \\
\text { abbreviation }\end{array}$ & Definition & Source \\
\hline LOD & Limit of detection & \\
\hline LOQ & Limit of quantification & \\
\hline MARAN & $\begin{array}{l}\text { Monitoring of Antimicrobial Resistance and } \\
\text { Antimicrobial Usage in Animals in the Netherlands }\end{array}$ & $\begin{array}{l}\text { https://www.wur.nl/en/Research- } \\
\text { Results/Projects-and- } \\
\text { programmes/MARAN-Antibiotic- } \\
\text { usage.htm }\end{array}$ \\
\hline ML & Maximum level & Regulation. 1881/2006 \\
\hline MOE & Margin of Exposure & \\
\hline $\begin{array}{l}\text { MRL } \\
\text { (veterinary } \\
\text { drugs) }\end{array}$ & $\begin{array}{l}\text { Maximum residue limit: the maximum } \\
\text { concentration of a residue of a pharmacologically } \\
\text { active substance that may be permitted in food of } \\
\text { animal origin. }\end{array}$ & $\begin{array}{l}\text { Regulation (EC) No 470/2009 } \\
\text { (Article 1.1a) }\end{array}$ \\
\hline $\begin{array}{l}\text { MRL } \\
\text { (pesticides) }\end{array}$ & $\begin{array}{l}\text { Maximum residue level: the upper legal level of a } \\
\text { concentration for a pesticide residue in or on food } \\
\text { or feed set in accordance with this Regulation, } \\
\text { based on good agricultural practice and the lowest } \\
\text { consumer exposure necessary to protect } \\
\text { vulnerable consumers }\end{array}$ & $\begin{array}{l}\text { Regulation (EC) No 396/2005 } \\
\text { (Article 3.2d) }\end{array}$ \\
\hline MRPL & $\begin{array}{l}\text { Minimum required performance limit (MRPL) } \\
\text { means minimum content of an analyte in a } \\
\text { sample, which at least has to be detected and } \\
\text { confirmed. It is intended to harmonise the } \\
\text { analytical performance of methods for substances } \\
\text { for which no permitted limited (sic) has been } \\
\text { established. }\end{array}$ & $\begin{array}{l}\text { Decision 2002/657/EC (Annex I, } \\
1.18 \text { ) }\end{array}$ \\
\hline RASFF & Rapid Alert System for Food and Feed & \\
\hline $\mathrm{RC}$ & $\begin{array}{l}\text { Recommended Concentration; CC } \beta \text { for screening } \\
\text { methods or CCa for confirmatory methods should } \\
\text { be lower than the RC }\end{array}$ & $\begin{array}{l}\text { CRL Guidance Paper (7 December } \\
\text { 2007) }\end{array}$ \\
\hline Risk & $\begin{array}{l}\text { A function of the probability of an adverse health } \\
\text { effect and the severity of that effect, consequential } \\
\text { to a hazard. }\end{array}$ & $\begin{array}{l}\text { Regulation (EC) No 178/2002 } \\
\text { (Article 3(9)) }\end{array}$ \\
\hline RPA & $\begin{array}{l}\text { Reference Point for Action: the level of a residue of } \\
\text { a pharmacologically active substance established } \\
\text { for control reasons in the case of certain } \\
\text { substances for which a maximum residue limit has } \\
\text { not been laid down in accordance with this } \\
\text { Regulation. }\end{array}$ & $\begin{array}{l}\text { Regulation (EC) No 470/2009 } \\
\text { (Article } 1(1 \mathrm{~b}) \text { ) }\end{array}$ \\
\hline $\begin{array}{l}\text { Risk-based } \\
\text { control }\end{array}$ & $\begin{array}{l}\text { Regular official controls on a risk basis, taking } \\
\text { account of: } \\
\text { (a) identified risks associated with animals, feed or } \\
\text { food, feed or food businesses, the use of feed or } \\
\text { food or any process, material, substance, activity } \\
\text { or operation that may influence feed or food } \\
\text { safety, animal health or animal welfare; } \\
\text { (b) feed or food business operators' past record as } \\
\text { regards compliance with feed or food law or with } \\
\text { animal health and animal welfare rules; } \\
\text { (c) the reliability of any own checks that have } \\
\text { already been carried out; and } \\
\text { (d) any information that might indicate non- } \\
\text { compliance. }\end{array}$ & $\begin{array}{l}\text { Regulation (EC) No 882/2004 } \\
\text { (Article 3(1.a)-(1.d) }\end{array}$ \\
\hline
\end{tabular}




\begin{tabular}{|c|c|c|}
\hline $\begin{array}{l}\text { Term/ } \\
\text { abbreviation }\end{array}$ & Definition & Source \\
\hline $\begin{array}{l}\text { Risk-based } \\
\text { monitoring }\end{array}$ & $\begin{array}{l}\text { Monitoring based on risks to humans: } \\
\text { (a) identified risks associated with animals, feed or } \\
\text { food, feed or food businesses, the use of feed or } \\
\text { food or any process, material, substance, activity } \\
\text { or operation that may influence feed or food } \\
\text { safety, animal health or animal welfare. }\end{array}$ & $\begin{array}{l}\text { Regulation (EC) No 882/2004 } \\
\text { (Article 3(1.a)) }\end{array}$ \\
\hline SDa & Netherlands Veterinary Medicines Institute & \\
\hline SSD & Standard Sample Description & EFSA, 2013a \\
\hline \multirow[t]{3}{*}{$\begin{array}{l}\text { Targeted } \\
\text { surveillance }\end{array}$} & $\begin{array}{l}\text { For Group A substances, surveillance should be } \\
\text { aimed at detecting the illegal administration of } \\
\text { prohibited substances and the abusive } \\
\text { administration of approved substances, } \\
\text { respectively. }\end{array}$ & $\begin{array}{l}\text { Directive 96/23/EC (Annex III, } \\
2 \text { and } 3 \text { ) }\end{array}$ \\
\hline & $\begin{array}{l}\text { The samples must be targeted taking account of } \\
\text { the following minimum criteria: sex, age, species, } \\
\text { fattening system, all available background } \\
\text { information, and all evidence of misuse or abuse of } \\
\text { substances of this group. }\end{array}$ & \\
\hline & $\begin{array}{l}\text { For Group B substances, surveillance should be } \\
\text { aimed particularly at controlling the compliance } \\
\text { with MRLs for residues of veterinary medicinal } \\
\text { products fixed in Annexes I and III to Regulation } \\
\text { (EEC) No } 2377 / 90 \text {, and the maximum levels of } \\
\text { pesticides fixed in Annex III to Directive } \\
86 / 363 / E E C \text {, and monitoring the concentration of } \\
\text { environmental contaminants. }\end{array}$ & \\
\hline
\end{tabular}




\section{Introduction}

The purpose of Directive $96 / 23 / \mathrm{EC}$ is to ensure that official controls on the animal production chain in the EU are harmonised. Every Member State draws up an annual sampling plan that meets the requirements of the Directive. Sampling levels and sampling frequencies at the farm and in the slaughterhouse are stated in Directive 96/23/EC and in Decision 97/747/EC. There are also extensive definitions of the substance or group of substances on which the inspection should focus. The main objective is enforcement with respect to the abuse of banned substances ('A substances') and authorised veterinary drugs (a subpart of the B substances; see Annex 1). Samples should be targeted to where illegal use or abuse is regarded as being most plausible. The Control Regulation (Regulation (EC) No 882/2004) applies to the other production chains (such as plant and feed production). That Regulation also requires Member States to draw up a multi-annual control plan. Unlike Directive 96/23/EC, the Regulation does not include rules for minimum sampling numbers or the substances to be analysed; it requires the audit to be based on a risk assessment. The difference in legal requirements is such that, under Directive 96/23/EC, more samples (5 to 6 times more) are examined than, for example, in the field of pesticide residues. However, there are no indications that risks due to dangerous substances in animal products are many times higher than those in plant products. The European Commission is planning a farreaching modernisation of official controls (COM(2013) 265). The new Regulation is expected to be published in the spring of 2017 and enter into force three years later. It will focus on risk-based control, allowing for the Member States to adapt national implementation according to their national priorities. Risk-based control comprises two steps (Van Asselt et al., 2013):

- risk-based monitoring, specifying what is to be sampled (what substance/product combinations and in what matrix)

- risk-based inspection, specifying where the sampling is to take place (at which stage in the chain, and on what holdings).

In the context of risk-based inspection, the Netherlands Food and Consumer Product Safety Authority (NVWA) has its own system for prioritising enterprises as "red", "yellow" or "green" on the basis of type of products and processes, business history, certification and other indicators. The frequency of inspections is commensurate with the classification of enterprises, with increased supervision for 'red' 'holdings and less for 'green' ones (Havinga \& Van Waarden, 2013). This report focuses on the implementation of risk-based monitoring, the first stage in risk-based control, specifying what substances have the highest priority in which animal species.

The purpose of this investigation was to draw up an action plan with a view to implementing a riskbased multi-annual National Plan (NP) for Residues in order to comply with the new Control Regulation. Risk in this case is defined as a combination of the probability of substances being found in certain products and their potential impact on public health.

An NP for Residues does not, however, need to focus exclusively on hazardous substances and products: random samples will also need to be taken in order to continue assessing consumer exposure to possible food safety hazards. Consideration will also have to be given to dealing with emerging risks. This investigation focused on an example supply chain, namely the red meat supply chain, which includes the meat of cattle, pigs, horses, goats and sheep. A study of the red meat supply chain was previously carried out by NVWA-BuRO. The results of that study were set out in a report in 2015 (NVWA, 2015). One of the follow-up actions that the report called for was to investigate the current monitoring of chemical substances under the NP for Residues with a view to making monitoring more risk-based, more efficient and more effective. The present report provides that follow-up. To this end, the following investigative questions were formulated:

1. How can current monitoring be made more effective?

a. How can substances be prioritised?

b. How can the optimum matrix be determined?

2. How can current monitoring be made more efficient?

a. Can samples be pooled?

b. How can emerging risks be detected? 


\section{Materials and Methods}

\section{$2.1 \quad$ Scope}

This study was geared to risk-based implementation of the NP for Residues, and focused on risk-based monitoring, the first step in a risk-based control plan. A working plan for the detection of high-risk companies, the second stage of risk-based control, was beyond the remit of this project. The action plan derived in this study addressed the red meat supply chain, but is based on a generic approach that is also applicable to other sectors. The plan was devised on the basis of risks to humans. Economic risks, political considerations and consumer perception can also play a role in the prioritisation of substances but were disregarded for the present study. The starting point was the list of chemical hazards from Directive 96/23/EC and chemical hazards that, according to the literature and expert statements, can be found in animal products, but are not referred to in the Directive.

\section{$2.2 \quad$ Literature review}

Existing NVWA reports on the red meat supply chain (NVWA, 2015; Van Rhijn \& Van der Voorde, 2014, 2015) were used in this study. Further literature searches were performed using Scopus and Google Scholar. The search terms used were: 'risk-based' AND 'sampling plan' OR 'monitoring plan' for the years 2006-2016. In addition, reports by authoritative organisations such as EFSA were used for information on possible residues in animal products.

\subsection{Monitoring data}

In order to obtain information on the occurrence of residues in animal products, the RASFF database of notifications for red meat for the period 2005-2014 was used, as were data from the KAP database for the years 2005 to 2014. This database is part of the ' Quality Programme Agricultural Products ', in which both the Dutch authorities and industry participate. The investigation made use of data provided by the NVWA and RIKILT. In order to obtain information on the use of antibiotics, we used data provided by the Netherlands Veterinary Medicines Institute (Stichting Diergeneesmiddelenautoriteit / $S D a)$.

\subsection{An alternative method of sampling for steroids}

In the National Plan, the control of natural hormones has traditionally been focused on blood with a Radio Immuno Assay for testosterone and oestradiol, with sampling taking place in the slaughterhouse. For the purposes of this study, a pilot experiment was performed to determine if the heel prick method could be used to show the presence of intact steroid esters, which provides direct evidence of exogenous administration. With this method, drops of blood are obtained by puncturing the skin with a lancet (the same as when the blood sugar level of diabetes patients is being checked), and a measured quantity of blood is then spotted on a carrier (similar to the heel prick test used on babies). This allows the use of Dried blood spot (DBS) cards (see Figure 1). The cards are then placed in a dried blood spot autosampler (DBSA), which desorbs the blood drop. The eluate is then analysed using a solid phase extraction (SPE) cartridge with the help of mass spectrometry (LC-MS/MS). 


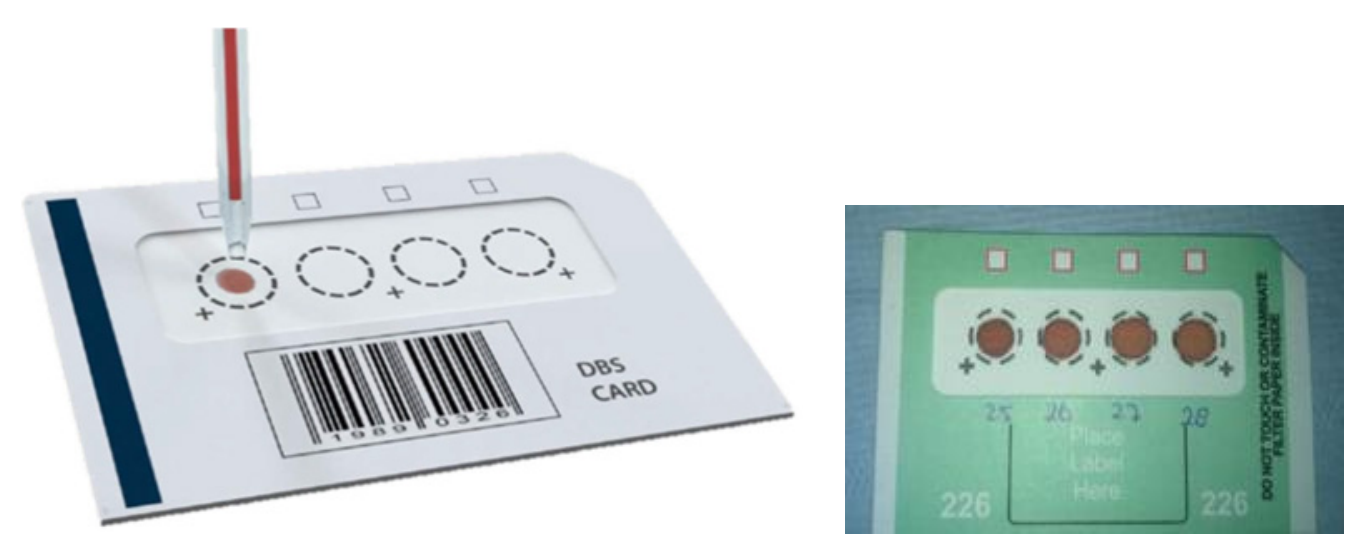

Figure 1 Left: DBS card on which a measured drop of blood has been spotted. Right: DBS card on which four drops of blood have been spotted.

A suitable LC-MS/MS method was established for measuring four steroid esters, which are used as a preparation mix (Sustanon): testosterone propionate, testosterone phenylpropionate, testosterone isocaproate and testosterone decanoate. A DBSA-LC-MS/MS method was then established to measure these esters on a DBS card. Since the components have to be measured at the lowest possible level, the components need to be derivatised so that the detection limits can be lowered. Methoxyamine (MOX) was used to derivatise the steroid esters. With the conventional LC-MS/MS method, this step takes place in the LC vial prior to the LC-MS/MS injection. As this research does not use an injection stage, derivatisation has to take place on the DBS card. The analysis was done using a Waters Acquity BEH C8 reverse phase UPLC column $(100 \times 2.1 \mathrm{~mm}, 1.8 \mu \mathrm{m})$ at $40^{\circ} \mathrm{C}$ and with a flow of $0.5 \mathrm{~mL} / \mathrm{min}$. Mobile phase A consists of $0.2 \%$ formic acid in $35 \% \mathrm{ACN}, 35 \% \mathrm{MeOH}$ and $30 \% \mathrm{H}_{2} \mathrm{O}$. Mobile phase $\mathrm{B}$ consists of $0.2 \%$ formic acid in $50 \% \mathrm{ACN}$ and $50 \% \mathrm{MeOH}$. A gradient profile was used. The DBSA was then connected to the LC-MS system. The MOX derivates were placed on a DBS card and the DBSALC-MS/MS method was optimised.

\subsection{Theoretical approach to pooling}

Calculations were done by Biometris using Genstat (VSNi, https://www.vsni.co.uk/software/genstat/) to determine whether samples could be combined to form a single composite sample. Biometris used a selection of KAP data for the 'steroid' group of substances in the urine of cattle and pigs for the years from 2005-2014.

The calculation of the optimum number of samples in a pool was based on the following principles (Patil, 1995):

- The procedure must not produce false negatives (100\% confidence that all samples $>$ Recommended Concentration (RC) are found).

- The maximum number of samples in a composite sample $\left(n_{\max }\right)$ is equal to the legal limit divided by the detection limit. The RC is used in the laboratory, allowing the maximum number of samples to be calculated as: $n_{\max }=R C / L O D$.

- If the concentration of a substance in a composite sample $(C$ ) is greater than $R C / n$ (where $n$ is the number of samples in the pool and $n \leq n_{\max }$ ), all the individual samples of the composite sample are retested.

\subsection{Laboratory experiments on pooling}

In order to determine the extent to which samples may be combined in a composite sample, analyses were performed with the ' $\beta$-agonist' group of substances. For this purpose, $25 \beta$-agonists were added to a blank cattle urine sample in a concentration equal to the RC as stated in the CRL Guidance Paper of 7 December 2007. The RC was used since this concentration is the minimum that a laboratory should be able to detect. If $\beta$-agonists are found to be above this concentration, the sample is 
reported as being non-compliant. Experiments were also carried out in which higher concentrations ( $2 x \mathrm{RC}$ and $3 \mathrm{x} \mathrm{RC}$ ) of $\beta$-agonists were added to urine samples. This was done in order to determine whether more samples could be aggregated if higher concentrations were expected in the sample.

$1,2,3$ or 4 blank urines were then added to the various enriched samples $(1 x, 2 x$ or $3 x$ RC). This was done in order to determine whether one positive sample could be detected if it was present in a composite sample of up to five urines. Two experiments were carried out to this end: dilutions with the same urine and dilutions with four other urines. The latter experiments more accurately reproduces real situations because, in practice, samples from different cows will be merged. A description of the RCs and the dilutions used are given in Annex 3. The substances were analysed with the help of LC-MS/MS and SOP A967. 


\section{Results and discussion}

\subsection{Background information on the red meat supply chain}

\subsubsection{Data on the red meat supply chain}

The following table provides an overview of the red meat supply chain. It provides information on the production and consumption of red meat in the Netherlands and the number of samples per animal species. The consumption data are based on the average daily consumption of the total Dutch population (including both people who eat and who do not eat meat) and average daily consumption for Dutch consumers who eat the specified type of red meat.

Table 1 Data on the red meat supply chain.

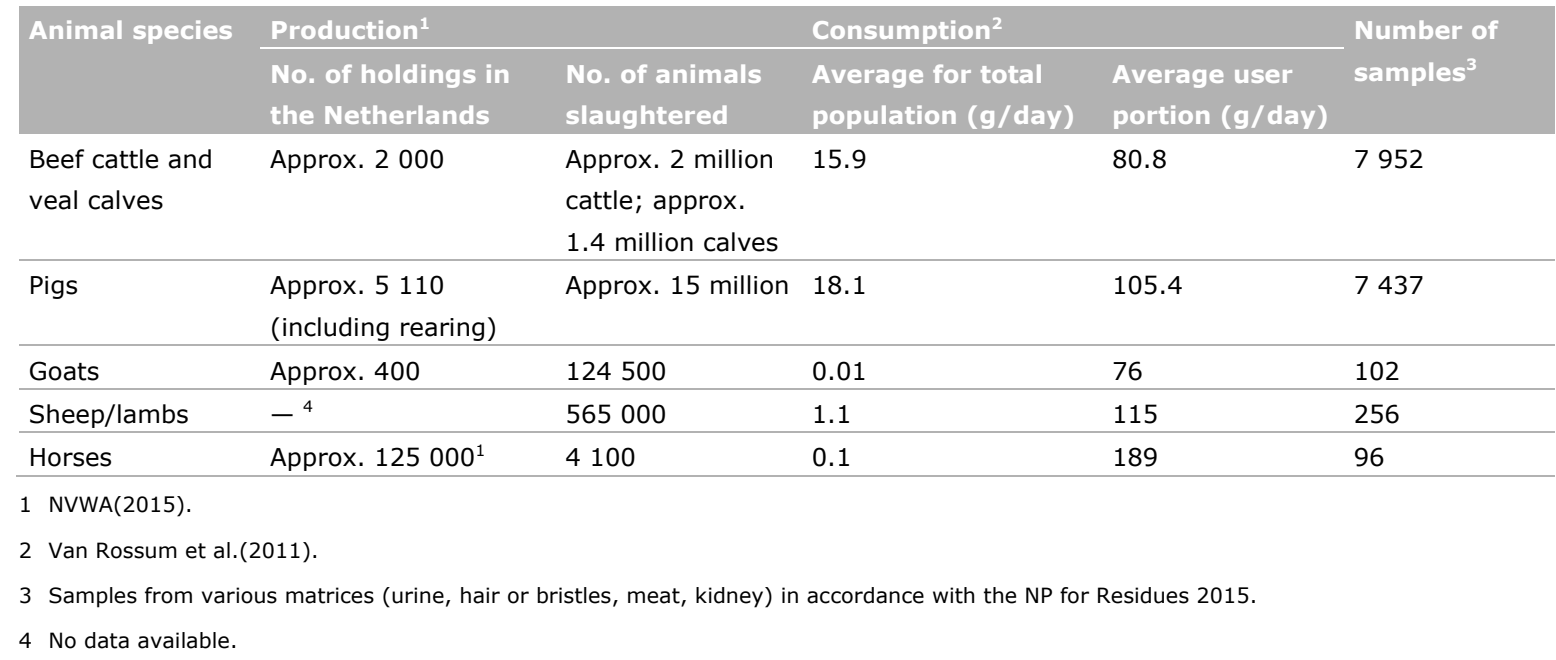

The number of samples taken for the various types of animal is slightly more than the minimum number of samples required under Directive 96/23/EC (see Table 2). Most of the samples are taken at the slaughterhouse. For example, samples for group B substances are almost all taken at the slaughterhouse. For cattle only, some samples are taken on the farm with a view to studying the B2f group. In accordance with Directive 96/23/EC, some group A compounds $(0.125 \%)$ are sampled from cattle on the farm. Because sampling for group $A$ and $B$ compounds in pigs is done in the slaughterhouse, one farm per 100000 pigs has to be sampled for group A compounds in accordance with Directive 96/23/EC. For this reason, a small proportion of group A compounds (0.001\%) are also sampled on the farm. Sheep, goats and horses are only sampled in the slaughterhouse. 
Table 2 Frequency of analysis (\% of the number of slaughtered animals) as laid down in Directive 96/23/EC and implemented in 2015.

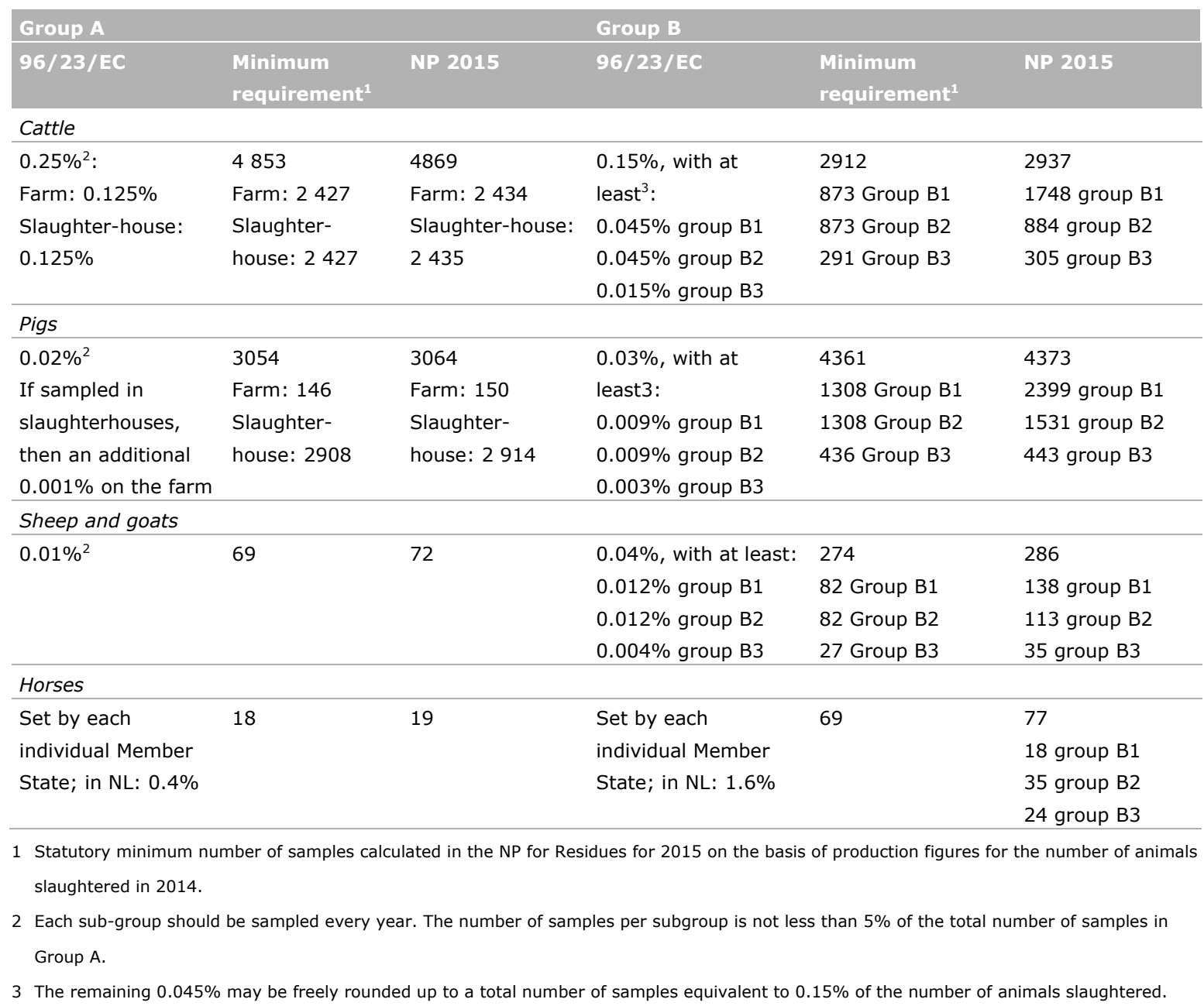

\subsubsection{Overview of the use of veterinary drugs}

Directive 96/23/EC includes the control of residues of authorised veterinary drugs (groups B1 and B2) and prohibited substances (group A). The use of authorised antimicrobial veterinary drugs was, for a number of years, recorded in the MARAN reports (https://www.wur.nl/en/Research-Results/Projectsand-programmes/MARAN-Antibiotic-usage.htm). Since 2009, this information has been held by the SDa. The most recent data for pigs and cattle are shown in Figure 2 (SDa, 2016b). Although the cattle sector includes both veal calves and dairy cows, only the data for veal calves are shown in Figure 2 because this group accounts for the vast majority of the veterinary drugs used. 


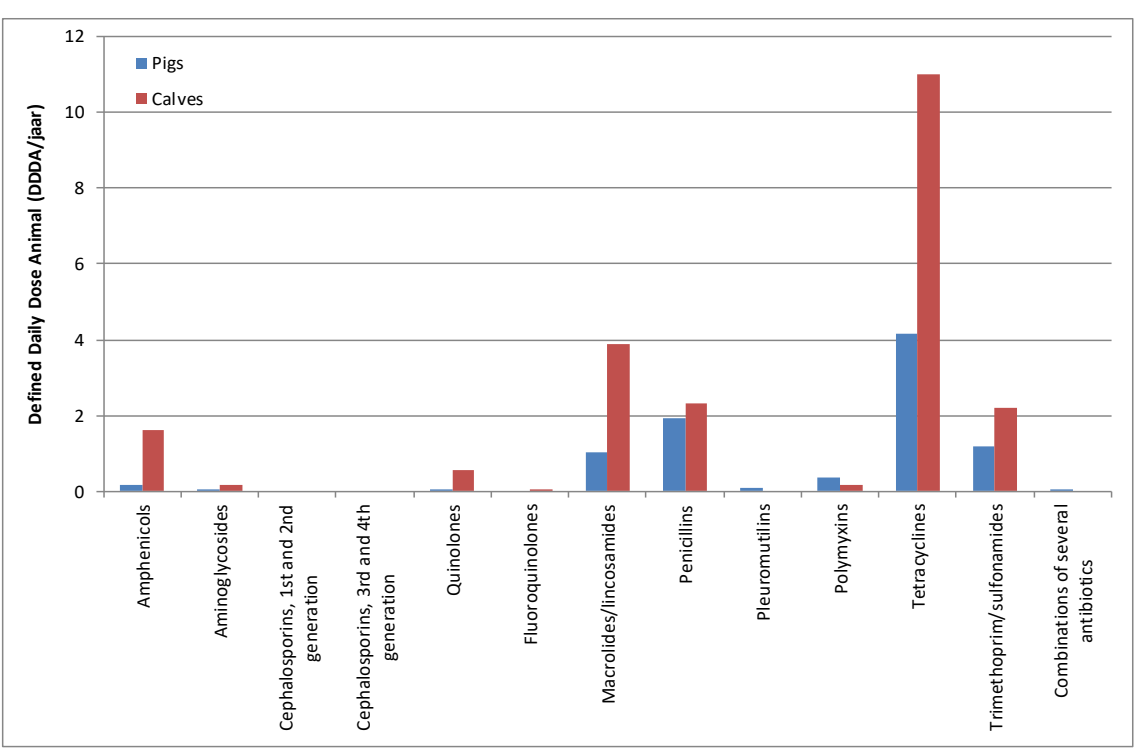

Figure 2 Use of antibiotics, broken down by pharmacotherapeutic group, for pigs and calves, expressed in DDDA/year (a unitless measure of antibiotic use, calculated as the sum of the treatable kilograms in an animal sector over a year, divided by the average number of kilograms of animals present in an animal sector) (SDa, 2016b).

A recently published survey shows that the use of antibiotics in horses is quite low. Highest use in 2014 was for trimethoprim/sulphonamides (0.35 DDDA/year), followed by penicillins

(0.13 DDDA/year). Other antibiotics were used in quantities below 0.1 DDDA/year (SDa, 2016a). Data on the sheep and goat sectors are not provided in the SDa reports (SDa, 2016b).

Only registered veterinary drugs may be used on farm animals, which is why no data are available on the use of unauthorised or illegal drugs (Van Ginkel \& Sterk, 2016). Experts from the Municipal Health Services (GGD) and the Royal Netherlands Association of Veterinarians (KNMvD) were approached, but they stated that they did not have information on illegal use of these drugs. They did, however, indicate that they had not encountered the use of illegal drugs in the Netherlands and believed that there was little or no use of such drugs here. Insights into the possible use of such drugs in animal husbandry can be obtained from experts in the field, EFSA reports, RASFF notifications and by analogy to the use of illegal drugs in human medicine. This information is currently being used by the NP for Residues Working Party in order to add substances/groups of substances to the NP and/or to adapt the frequency of analysis, as appropriate. This usually entails minor adjustments to the programme.

\subsubsection{Legal limits applying to the red meat supply chain}

Under Directive 96/23/EC, animal products are monitored for residues of authorised and unauthorised veterinary drugs and for substances and contaminants present in the environment. If substances are found to be above the legal or semi-official limits, they are reported as being 'non-compliant'.

\subsubsection{Legal limits on substances having an anabolic effect and unauthorised substances (group A)}

Directive 96/22/EC prohibits the use of certain substances in the animal production chain; these substances are listed in Annex I to Directive 96/23/EC as group A substances (see also Annex 1 to this report). Residues of these substances may not be found in matrices of farmed animals (the exception being natural substances, although these must not exceed their natural levels). In other words, these substances are subject to 'zero tolerance'. The analytical methods used for testing for residues are subject to the requirements of Decision 2002/657/EC. Each method has lower limits below which it is not possible to make reliable pronouncements on the presence or absence of a substance or on the quantitative concentration of a substance. According to Decision 2002/657/EC, the CCa is a decision limit used in a confirmatory method. This CCa can be regarded as an action limit and is derived from the method of analysis used, as is the $C C B$ (the detection limit). It can be said with certainty that a 
substance that is above the CCa has been detected. The Decision sets out MRPLs (minimum required performance limits) for a limited number of substances (chloramphenicol, metabolites of some nitrofurans, medroxyprogesterone acetate and the sum of malachite green and leucomalachite green). Every official laboratory should be able to achieve these limits when testing for these substances. These MRPLs were established to ensure that there are no longer any differences in import controls between Member States, i.e. to prevent products being rejected in one country but not in another. Decision 2005/34/EC applied these MRPLs irrespective of the matrix and specified that the MRPL was to function as an action limit. Products with levels below the action limit no longer had to be denied access to the EU or be destroyed. It was also decided, in consultation with the Member States and the Commission, that these MRPLs should be used not only for imported products, but also for EU products. The fact that levels of a substance exceed the MRPL does not necessarily equate with a toxicological effect. In order to take into account the effects on public health, Reference Points for Action (RPAs) were established pursuant to Regulation (EC) No 470/2009. According to that Regulation, an RPA is an analytical limit that is justified from a toxicological point of view. The EFSA was asked to draw up a Guidance document for these RPAs, which was published in 2013 (EFSA, 2013a). RPAs will also be determined for all other prohibited substances that do not have an MRPL, pursuant to Regulation (EC) No 470/2009. The EFSA will assess these substances and propose RPAs, and the European Commission, together with the Member States, will take a decision on adopting them. The RPAs mentioned in the EFSA Guidance are not (yet) enshrined in law. In 2007, the EU Reference Laboratories (EURLs) drew up guidelines for prohibited substances with a view to harmonising controls on such substances in the EU (CRL, 2007). These guidelines refer to RCs (Recommended Concentrations); the RCs can be seen as 'semi-official' MRPLs: analytical limits that the Member States should be able to comply with when testing for substances. The RCs are used for reporting purposes. If substances are found to be above the RC, the sample is reported as 'noncompliant'.

\subsubsection{Legal limits on veterinary drugs (group B1 and B2)}

The MRLs for residues of authorised active substances used in veterinary drugs are to be found in the Annex to Regulation (EU) No 37/2010, those for residues of carried-over feed additives in Regulation (EC) No 124/2009, and those for residues of certain other additives in separate regulations.

\subsubsection{Legal limits on other substances and contaminants present in the environment (group B3)}

The statutory maximum limits (MLs) of certain contaminants and natural substances such as mycotoxins are listed in the Annex to Regulation (EC) No 1881/2006. These MLs are set as low as possible i.e. 'as low as reasonably achievable' (the 'ALARA principle') through the implementation of good practices in accordance with Regulation (EEC) No 315/93. Besides these MLs, dioxins also have action limits. If the dioxin content is found to be above the action limit (but below the $\mathrm{ML}$ ), producers and public authorities should seek to identify the source of contamination. The Annexes to Regulation (EC) No 396/2005 set out maximum residue levels (MRLs) for pesticides.

\subsubsection{Overview of residues in animal products}

Every year, an NP for Residues is drawn up which sets out the number of samples and a list of individual substances to be analysed within the various groups of substances referred to in Annex I to Directive 96/23/EC. The substances in question are group A substances (substances having anabolic effect and unauthorised substances): group A1, stilbenes, their derivatives and esters; group A2, antithyroid agents; Group A3, steroids; group A4, resorcylic acid lactones, including zeranol; group A5, $\beta$-agonists; group A6, prohibited substances; and group $B$ substances (veterinary drugs and contaminants); group B1, antibiotics; group B2, other veterinary drugs, and group $\mathrm{B}_{3}$, natural substances and contaminants, such as organochlorine compounds, organophosphorus compounds, heavy metals and mycotoxins.

The list of substances included in the current NP for Residues was determined in the light of various factors: the legal provisions governing the substance, the route of administration (feed, drinking water, individual or group treatment), animal category (e.g. beef cattle or dairy cows), possible carryover to the animal, toxicity of the substance, use of the substance, monitoring results and RASFF 
notifications. In order to select the matrices and production phase, areas were selected where the chances of residues being detected were highest, e.g. specific production systems, animals of a certain age if there are indications that use is higher among that age group.

The NP for Residues Working Party discusses the NP annually in order to decide whether adjustments are necessary in the light of current analytical capabilities and information available from the EURLs, NRLs and official laboratories. The Working Party brings together representatives of the Ministry of Health, Welfare and Sport and the Ministry of Economic Affairs, policy and implementing bodies, RIKILT and the NVWA. The number of samples to be taken is calculated on the basis of the previous year's production figures.

The NVWA's current monitoring focuses on prohibited and undesirable substances (e.g. growth hormones and $\beta$-agonists), antibiotics (including prohibited antibiotics) and contaminants such as heavy metals. The proportion of samples found to be non-compliant in 2014 was low (0.2\%). Of the approximately 8000 samples of pigs and cattle in the slaughterhouse, only $0.15 \%$ and $0.18 \%$ respectively were found to be non-compliant in 2014. The non-compliant findings mainly relate to thiouracil (Group A2) in cattle and steroids (A3) and antibiotics (B1) in pigs. Furthermore, the kidneys of animals for slaughter were sometimes found to have an elevated concentration of cadmium. Because cadmium accumulates in the organs over time, the kidneys of cattle aged over two years are no longer used for human consumption in the Netherlands. With respect to thiouracil, the EU is discussing a proposal to raise the limit from $10 \mu \mathrm{g} / \mathrm{L}$ to $30 \mu \mathrm{g} / \mathrm{L}$. This higher limit would mean almost no excess values in cattle. The number of samples for other types of red meat is limited but compatible with Directive 96/23/EC: 180 samples for horsemeat in 2014 and 461 samples for goat meat and sheep meat. In the latter category, three samples $(0.65 \%)$ were found to be non-compliant (NVWA, 2015). Non-compliant findings for individual years are shown in Figures 3-5 (Dop, 2016; Van Rhijn \& Van der Voorde, 2014, 2015). The percentages of non-compliant analyses by group of substances are very low and vary from year to year. These figures show that the percentage of noncompliant analyses for antithyroid agents (Group A2) is highest in cattle. For the other substances, the percentage of non-compliant analyses in goats and sheep is higher than in the other types of animal (Dop, 2016; Van Rhijn \& Van der Voorde, 2014, 2015).
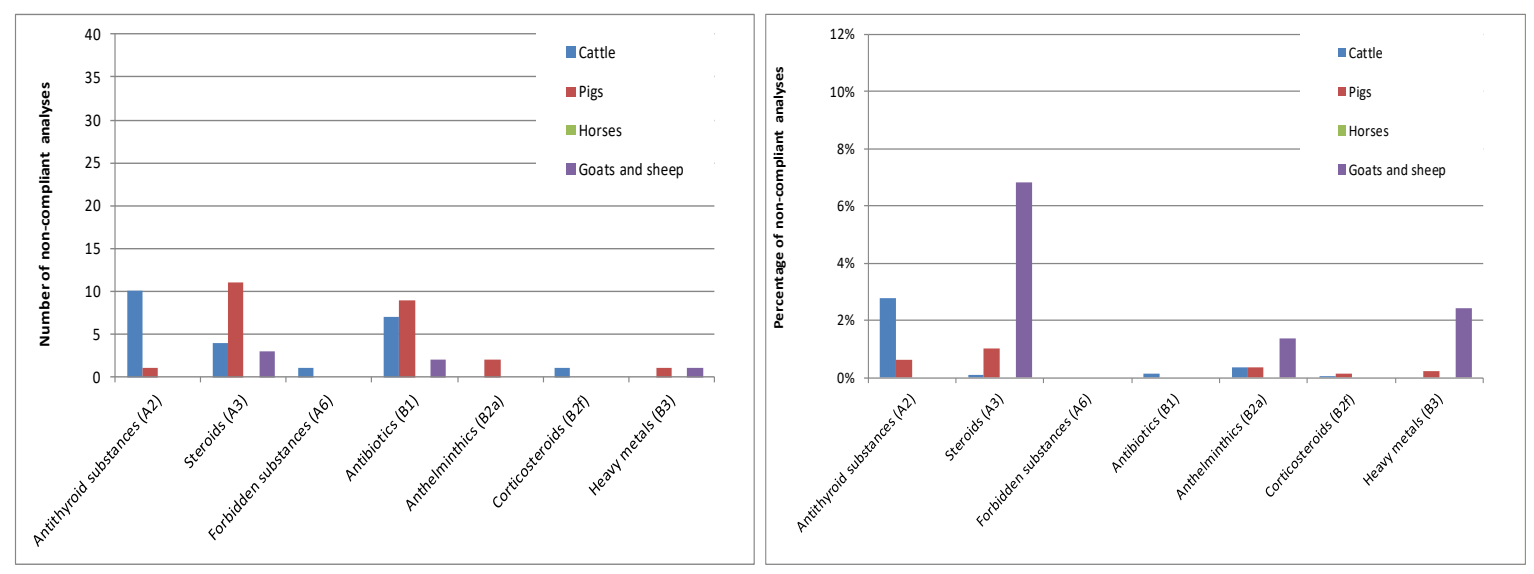

Figure $3 \quad$ Number of non-compliant analyses by group of substances and the percentage of noncompliant analyses within a group of substances in the Netherlands in 2013 (Van Rhijn \& Van der Voorde, 2014). 


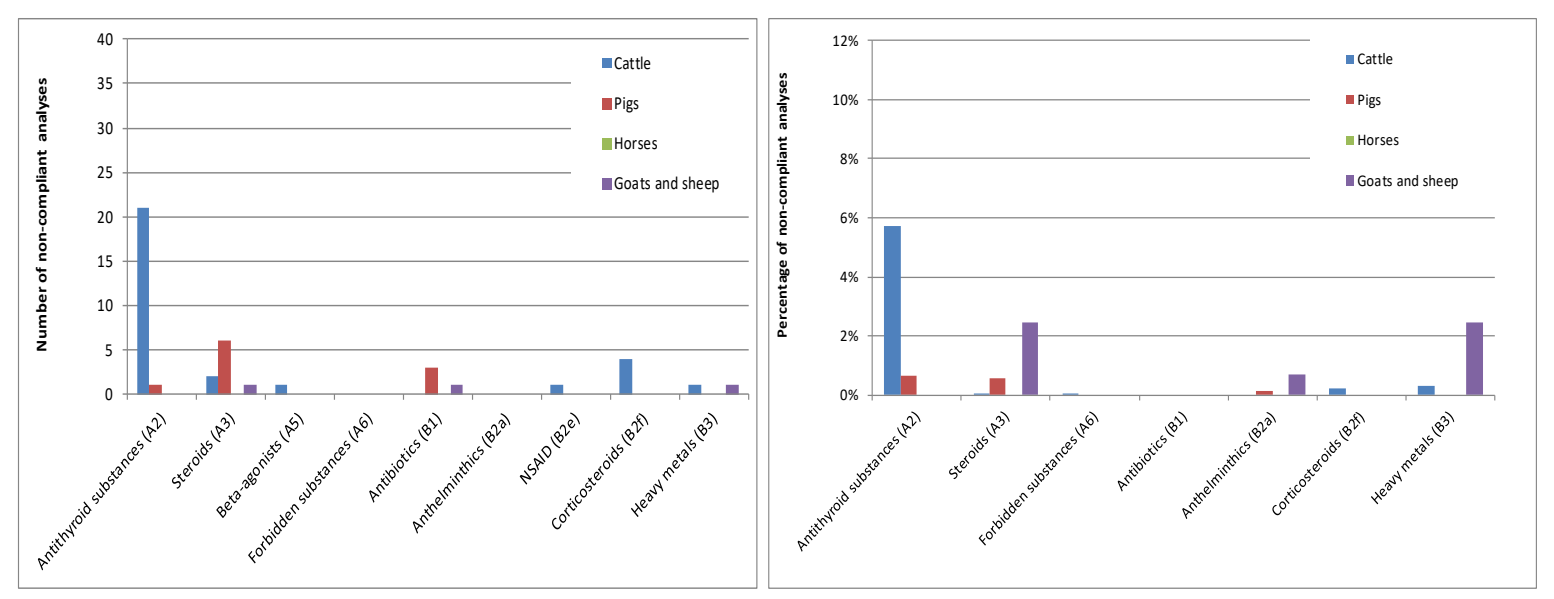

Figure $4 \quad$ Number of non-compliant analyses by group of substances and percentage of noncompliant analyses within a group of substances in the Netherlands in 2014 (Van Rhijn \& Van der Voorde, 2015).
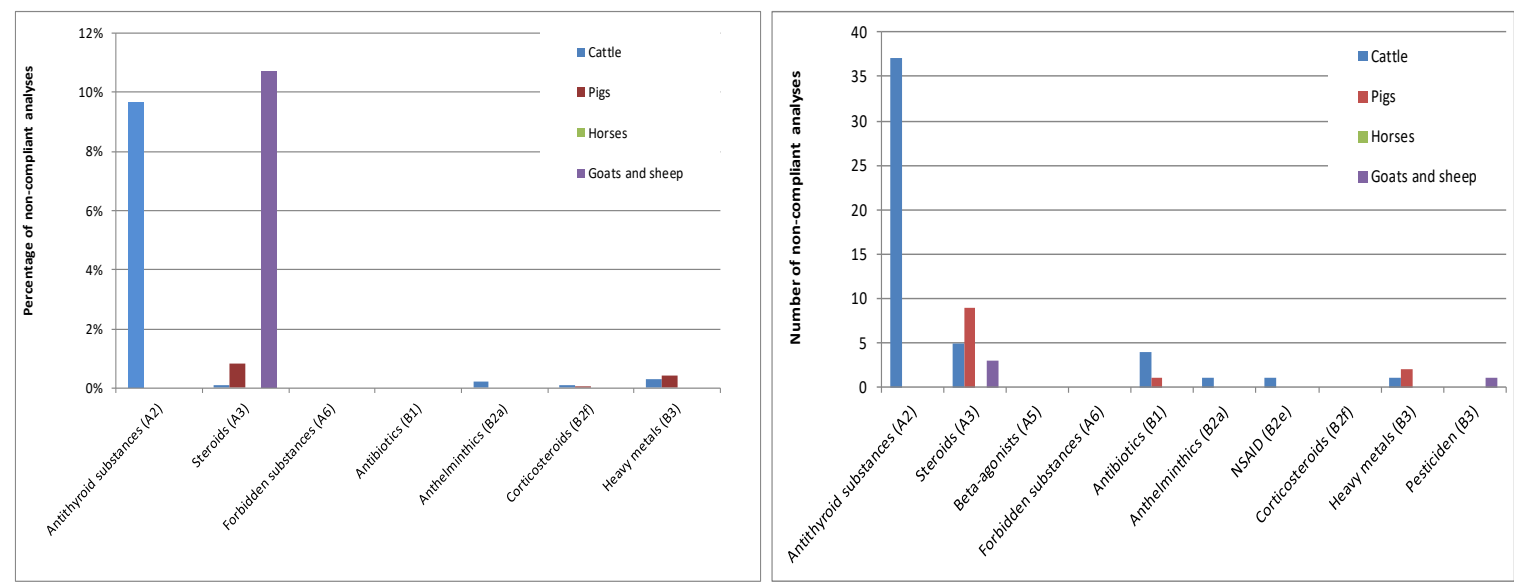

Figure $5 \quad$ Number of non-compliant analyses per group of substances and the percentage of noncompliant analyses within a group of substances in the Netherlands in 2015 (Dop, 2016).

European data gathered by the EFSA show that the percentage of non-compliant samples in 2014 was on average $0.42 \%, 0.28 \%, 4.67 \%$ and $0.32 \%$ for beef, pork, horsemeat, and sheep meat + goat meat, respectively. The highest number of non-compliant samples was for the 'heavy metals' group of substances (see Figure 6). For cattle, this was mainly copper, while it was mainly copper and mercury for pigs, and mainly cadmium for horses (EFSA, 2016). Copper is an essential trace element and may be used as an additive in compound feed for various types of animal, including pigs. As cupreous substances can be used as plant protection products, the MRLs in Regulation (EC) No 396/2005 have, since 2009, been used for assessing concentrations of copper and mercury in animal products. The MRL for copper components in red meat is $5 \mathrm{mg} / \mathrm{kg}$; for organs (liver and kidney) it is higher, at $30 \mathrm{mg} / \mathrm{kg}$ (Regulation (EC) No 396/2005)). 

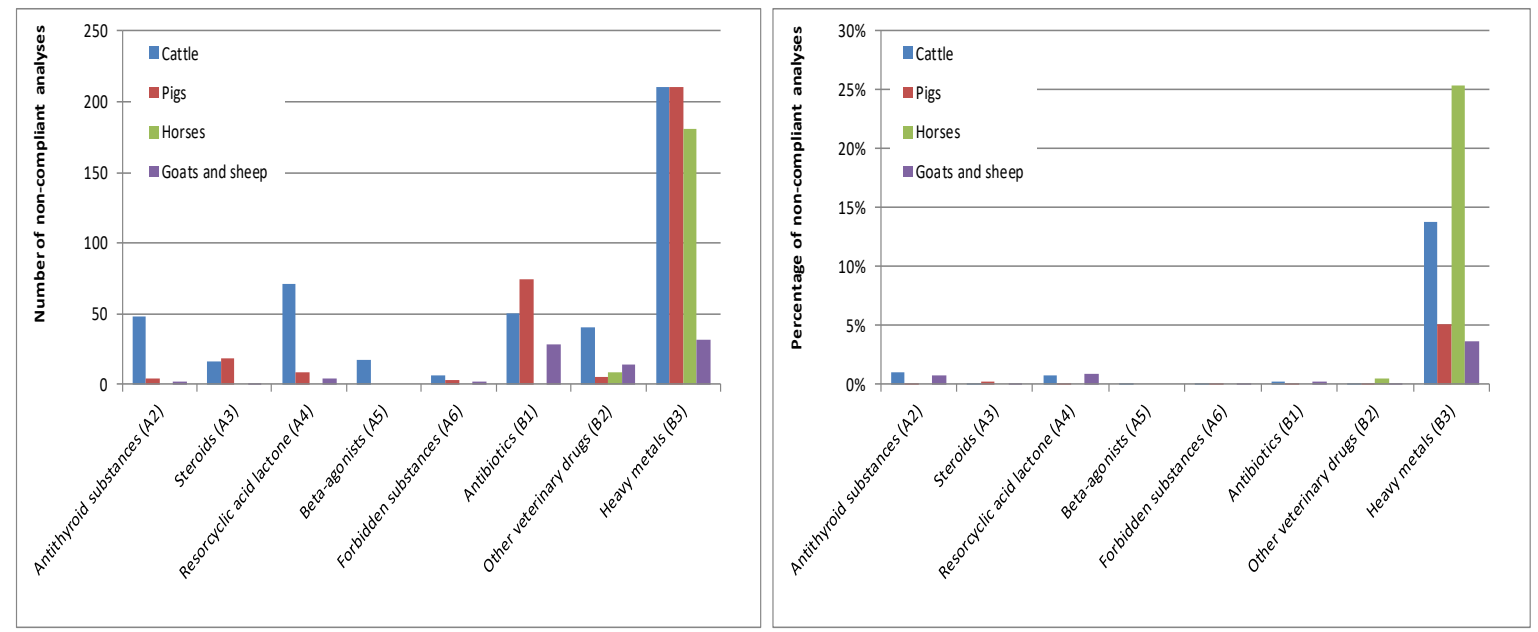

Figure 6 Number of non-compliant substances by group of substances and the percentage of noncompliant analyses within a group of substances in Europe in 2014 (EFSA, 2016).

RASFF data show that most notifications for red meat concerned residues of veterinary drugs (Figure 7). Figure 8 shows, per animal species, which veterinary drugs were reported. The substance most frequently reported in beef was ivermectin in meat imported from Brazil. Ivermectin is an authorised anti-parasitic with an MRL of $30 \mu \mathrm{g} / \mathrm{kg}$ for meat in the EU. In the case of horsemeat, the most frequently reported substance was phenylbutazone in meat imported from the United Kingdom and Poland. Phenylbutazone is regularly used as a painkiller for racing and pet horses, which are not directly intended for meat production. The use of medication in horses must be recorded in an equine passport, on the basis of which it can be determined whether an animal is fit for slaughter.

Phenylbutazone is not registered for use on horses in the Netherlands and should therefore not be used. Abroad, phenylbutazone is mainly used for race horses. If this substance is used, products obtained from the treated animal may not enter the food chain (EFSA \& EMA, 2013). Notifications for pork related mainly to infringements of the MRL for sulphadiazine and the presence of the banned substances chloramphenicol, furazolidone and nitrofurazone.

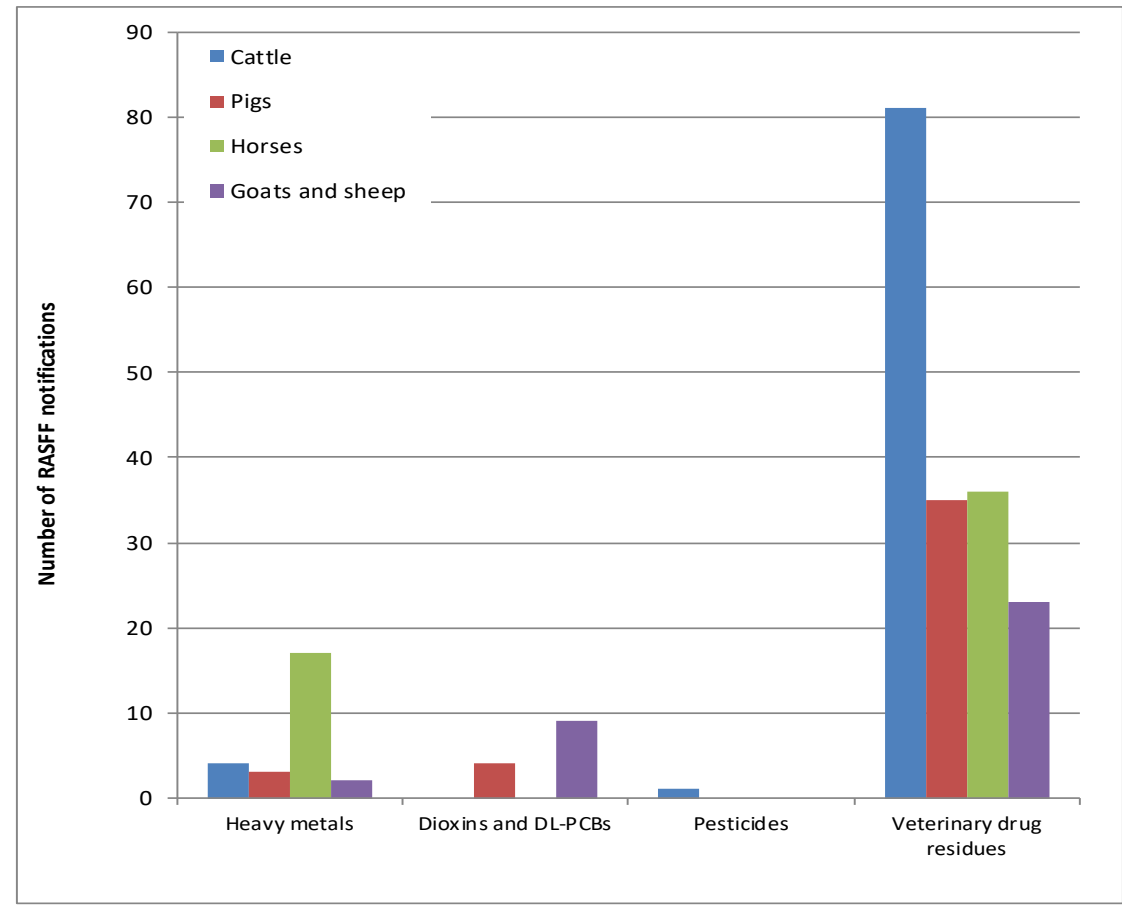

Figure $7 \quad$ Number of RASFF notifications for chemical hazards in red meat between 2005 and 2014. The 'veterinary drugs' group comprises both authorised antibiotics and prohibited substances. 


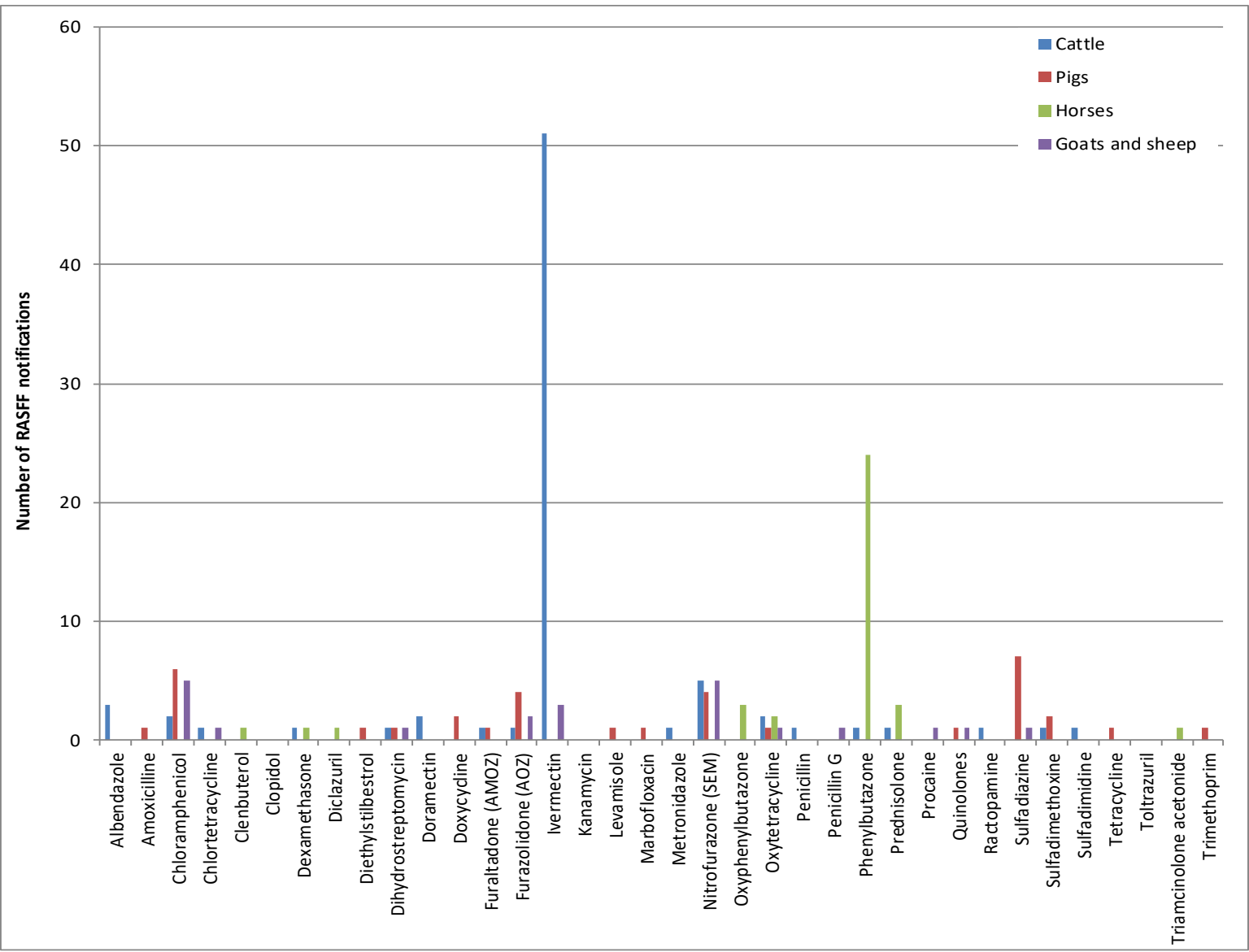

Figure $8 \quad$ Number of RASFF notifications concerning veterinary drugs in red meat between 2005 and 2014.

\subsubsection{KAP database}

A major part of the Dutch monitoring data on the red meat supply chain is stored in the KAP database. This database is part of the Quality Programme for Agricultural Products, which is characterised by close cooperation between the authorities and the agricultural sector. The KAP data on red meat are obtained primarily from measurements that are taken as part of the NP for Residues. The data can be used as input for implementing a risk-based monitoring plan. It is important that the data are up to date. The KAP database is not yet complete. The only data with a bearing on red meat that are up to date relate to halogenated compounds; data for other compounds are available only for the period to 2012.

The KAP data must meet certain quality criteria. For example, the supply of data is checked on an annual basis so that inconsistencies can be detected. It is also important that all relevant data are stored, such as the sampling strategy (random or targeted), production method (organic, conventional etc.), type of product and product treatment (raw, processed, etc.) (Van Gorcum, 2013). The RIKILT monitoring data are stored in LIMS. These data are transferred to KAP automatically as far as possible. To this end, EFSA's FoodEx2 product classification is used, so as to ensure that product names are consistent (Van Donkersgoed, 2016). For animal feed, a classification is used that is based on the EU product number, which makes it possible to link more information to a sample. The RIVM is currently working towards a further strengthening of the data quality requirements (Van Donkersgoed, 2016). RIKILT is also working on an inventory as part of its 'Big Data' project, with a view to improving the LIMS database so that data can more easily be used for various purposes and sent to EFSA. With this in view, EFSA has compiled a manual for the Standard Sample Description (SSD) (EFSA, 2013a). The manual provides a format in which to store analytical results in (national) monitoring programmes. There are 20 mandatory data fields that describe the unique features of a sample. These fields include, among others, the date of sampling, date of analysis, origin of the sample, analysis results, 
and units. EFSA'S new SSD2 database specifically requires the input of detection limits (LOD or LOQ) and all quantitative results (> LOQ) (EFSA, 2013a). Currently, concentrations of veterinary drugs are only stated in the KAP database if they exceed the MRL. All measurements that are $<M R L$ are reported as ' $O$ '. As a result, it is often unclear whether there are positive samples ( $>$ LOD) that are nevertheless below the MRL. There is a direct correlation between the volume of quantitative data that is stored and the information that can be obtained on substances that are liable to be found in animal products. In order to use the data as input for risk-based monitoring, it is also important to indicate the sampling strategy (random or targeted). Generally speaking, there is a direct correlation between the volume of stored data concerning a sample and how successfully those data can be used for analysis. A major limitation of RASFF notifications and EFSA reports, and sometimes KAP data, is that values are only reported when they exceed the legal limits.

\subsubsection{Current analytical methods}

Various techniques are used to analyse the substances and groups of substances that are currently included in the NP for Residues (Table 3). There is a Europe-wide consensus on these techniques, although the precise details of how the analysis (SOP) is implemented may vary from country to country. In several cases, an initial screening is done. Suspicious results are then further analysed and confirmed (i.e. identified and quantified). Group A compounds are mainly analysed using GC-MS/MS or LC-MS/MS. In the case of chloramphenicol, screening is first carried out using an enzyme immunoassay (EIA). Group B1 compounds (authorised antibiotics) are first screened using a bacterial inhibition test, after which the results for suspect samples are confirmed using LC-MS. Other veterinary drugs in group B2 are mainly analysed using GC-MS, LC-MS and HLPC-FD. Group $B_{3}$ comprises a varied group of substances, which is therefore analysed in various ways. Organochlorine compounds (including PCBs), together with around 60 other pesticides, are analysed using GC-MS/MS. Organophosphorus compounds and carbamates are analysed using LC-MS/MS. Positive results are confirmed using the same methods. Cadmium and lead are analysed using electrochemical atomic absorption spectrometry ETAAS) and mercury is analysed using cold vapour atom fluorescence spectrometry (CV-AFS). Lastly, the mycotoxins zearalenon, zearalenol, zearalanon and zearalanol are analysed using LC-MS. These substances are measured as they are also resorcyclic acid lactons (RALs) (Group A4).

Table 3 Overview of analytical methods currently used for red meat.

\begin{tabular}{|c|c|c|}
\hline Group of substances & Screening & Confirmation \\
\hline A1: Stilbenes, stilbene derivatives, and their esters & No & GC-MS/MS or LC-MS/MS \\
\hline A2: Antithyroid agents & No & LC-MS/MS \\
\hline A4: Resorcylic acid lactones including zeranol & No & LC-MS/MS \\
\hline A5: $\beta$-agonists in liver & No & LC-MS/MS \\
\hline A6: Nitrofurans and other prohibited substances & No & LC-MS/MS \\
\hline A6: Chloramphenicol & Yes (EIA) & LC-MS/MS \\
\hline B1: Antibiotics & Yes (NAT-MIA) & LC-MS \\
\hline B2a: Anthelmintics & No & LC-MS/MS \\
\hline B2d: Sedatives & No & LC-MS/MS \\
\hline B2e: Non-steroidal anti-inflammatory drugs (NSAID) & No & LC-MS/MS \\
\hline B2f: Other pharmacologically active substances & No & LC-MS/MS \\
\hline B3a: Organochlorines (including PCBs) & No & GC-MS/MS \\
\hline B3B: Organophosphorus compounds & No & LC-MS/MS \\
\hline B3C: Chemical elements & No & ETAAS/CV-AFS \\
\hline B3d: Mycotoxins & No & LC-MS/MS \\
\hline
\end{tabular}


Directive 96/23/EC does not explicitly describe the matrix to be sampled in order to comply with monitoring obligations; a distinction is, however, made as to the stage at which samples are to be taken (at the farm or at the slaughterhouse). The matrix sampled differs depending on the residue distribution in the animal and the practical feasibility of sampling. Sampling at the farm must not be invasive, which is why most sampling is done on urine. At the point of slaughter, kidneys, livers and meat are sampled. The choice of matrix depends on practical feasibility, the highest probability of detecting residues, and the legal provisions on matrices. For example, most growth promoters are quickly metabolised, and the chance of detecting them at the slaughtering stage is relatively small (Van Ginkel \& Sterk, 2016). On the other hand, for veterinary drugs, only the levels found at the time of slaughter are relevant. Testing urine for antibiotics at the farm serves at best to check on record keeping of veterinary drugs on that farm. Where statutory withdrawal periods are adhered to, antibiotic concentrations will have fallen below the MRL by the time of slaughter and there is no infringement. In the primary stage (at the farm) urine and hair or bristles are mainly sampled, and substances in group A and some in group B2f (other substances with pharmacological activity) are analysed. Most of the samples for the NP for Residues are taken at the slaughterhouse (NVWA, 2015). For example, heavy metals are sampled in the slaughterhouse because they accumulate in the kidneys and liver. An overview of matrices that are currently sampled for the various substances is given in Table 4.

Table 4 Overview of current matrices for the analysis of various groups of substances in red meat.

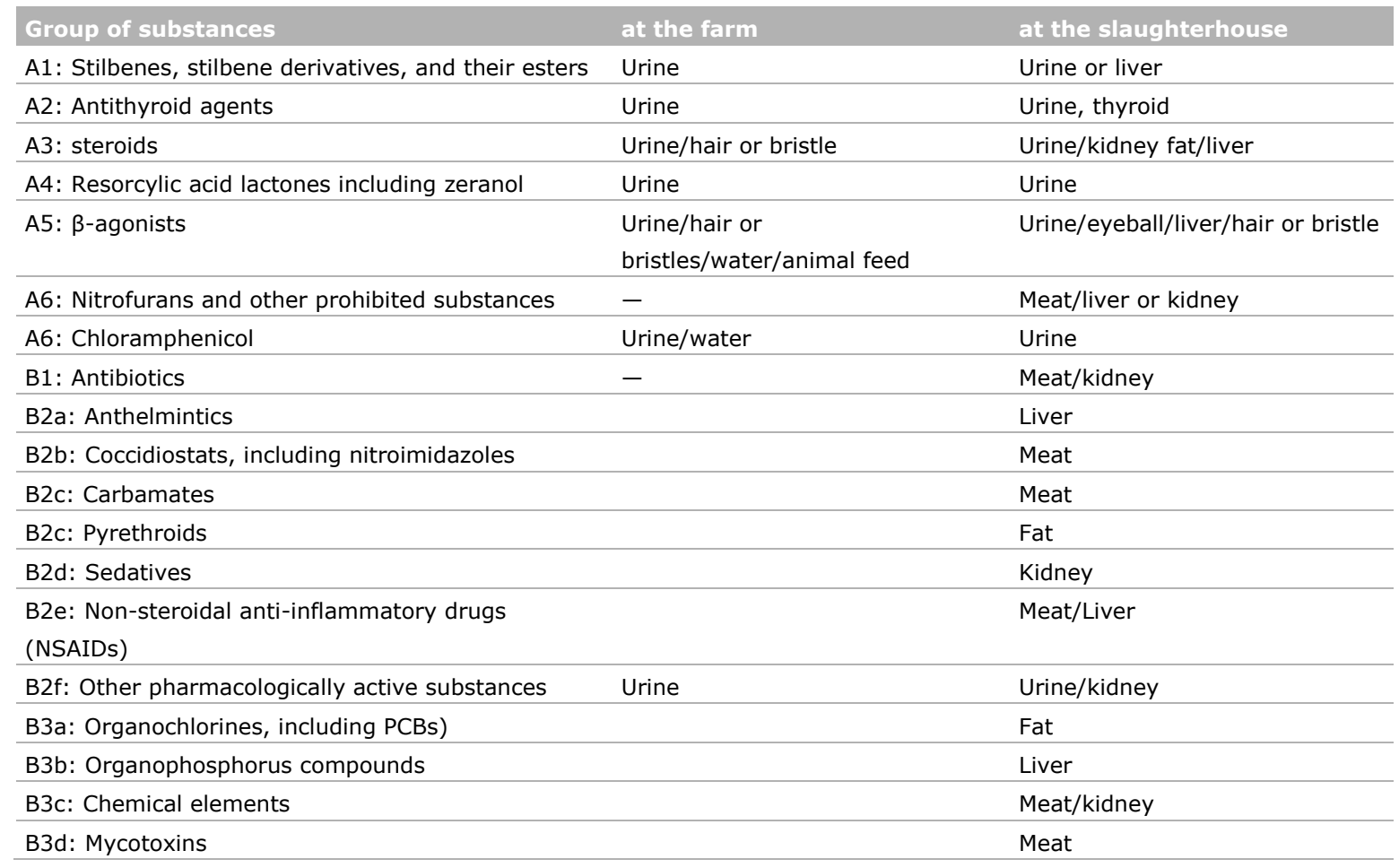

\subsection{Ensuring effective monitoring ${ }^{1}$}

\subsubsection{Introduction}

In order to ensure that the monitoring of undesirable substances is as effective as possible, it is important to focus on substances with the highest risk. Risk is a combination of the probability that a substance is present in a product (prevalence) and the effects of that substance on humans (seriousness). The literature describes various methods for prioritising substances. These methods range from qualitative methods, based entirely on expert knowledge, to semi-quantitative methods

\footnotetext{
1 This section has been submitted as a research paper to a peer reviewed scientific journal.
} 
using scores and quantitative methods using a risk assessment based on exposure assessments and dose response modelling (Van der Fels-Klerx et al., 2016). Quantitative methods such as risk assessments require considerable time, budgetary resources and data, and are therefore less wellsuited as a means of ranking a large group of substances. Qualitative and semi-quantitative methods would appear most appropriate for prioritising substances for monitoring programmes. These methods offer the possibility of including various criteria. Substances should preferably be classified as objectively as possible, using the available data. If no data are available, experts can be asked for their inputs. Annex 2 provides an example of a semi-quantitative method. Given the large number of substances that have to be prioritised in order to determine whether they should be included in the NP for Residues, it was decided to use a qualitative method incorporating a decision tree.

\subsubsection{Compiling the list of substances}

In order to identify the substances that should be included in the NP for Residues, a decision tree can be used. The EFSA uses a decision tree, which serves to attribute substances to four risk categories: negligible, low, medium and high risk (EFSA, 2012a, 2012b). The criteria underlying this decision tree have not, unfortunately, been substantiated, and the decision tree is therefore not transparent. The advantage of decision trees is that this method is less time-consuming than a semi-quantitative risk classification based on scores, as described in Annex 2. In order to arrive at a transparent system, the criteria used in the decision tree must have a scientific basis and the decision tree has to be used for each animal species and animal product (meat, milk, eggs and honey) so as to obtain a prioritised list per animal species.

For the purposes of this study, three different decision trees were designed, because the task of classification necessitated different questions for individual groups of substances. This is because some substances enter the animal via its environment or via its feed (natural substances, contaminants and pesticide residues), while other substances are directly administered to the animal. Substances that are directly administered may be authorised veterinary drugs, which have been assessed for safety and therefore do not present a danger to human health if used correctly, or substances whose use in animals is prohibited because of their toxicological effects or because they have not been assessed for safety. The various routes of exposure and differences in the toxicity of substances necessitated various types of questions for these groups of substances. If just one decision tree were used to process all of these substances, it would be excessively complex. Three decision trees were therefore created:

- Group I: Prohibited substances (Figure 9)

- Group II: Natural substances, contaminants and pesticide residues (Figure 10)

- Group III: Authorised active substances of veterinary drugs and feed additives (Figure 11).

It is recommended to create a Working Party (WP) to run the substances through the decision trees. The WP should comprise experts involved in implementing the NP and experts in toxicology. The decision trees are used for each animal species and animal product. Substances with similar noncompliance levels, such as tetracyclines and sulphonamides, can be processed at group level. Most of the other substances are processed individually because absorption differs per animal and/or because the MRL or ML are liable to differ. One could also, as a starting point, include in the NP all substances that have been reported as non-compliant in the Netherlands or the EU in the last five years.

Certain questions need to be answered for each decision tree. The following sections take a closer look at the decision trees and develop the questions in greater detail. When a substance is run through a decision tree, it is eventually ascribed to a particular risk class, depending on the possible risk it poses to humans:

- High priority: this substance/group of substances has high priority for inclusion in a risk-based monitoring plan for animal matrices because of potential risks to consumer health.

- Medium priority: this substance/group of substances has medium priority for inclusion in a riskbased monitoring plan for animal matrices because of occasional potential risks to consumers.

- Low priority: this substance/group of substances has low priority for inclusion in a risk-based monitoring plan for animal matrices because of the very low or negligible risk it poses to the consumer. However, if this substance/group of substances were included in a chemical- analytical multi-method for substances/groups of substances with high or medium priority, there is no reason for it to be removed unless precisely that substance has a negative effect on the sensitivity of the method. 
Groups of substances that are ascribed to the medium-priority or low-priority class may nevertheless be given a high priority in the NP for Residues in order to reflect policy, social or economic objectives.

\subsubsection{Decision tree for prohibited substances, Group I (Figure 9)}

The use of a large number of substances in livestock production is explicitly banned. This is partly because safe use is not thought possible (after a safety assessment) and partly because a safety assessment has not been performed. Safety assessments are not carried out on each individual substance in all explicitly prohibited groups of substances; for example, the use of virtually all $\beta$ agonists is prohibited without individual $\beta$-agonists having to be specifically deemed unsafe for use. However, for this decision tree, it is assumed that residues of substances in animal products always present a danger to humans, unless the opposite has been scientifically demonstrated. This decision tree is used for the following substances/groups of substances:

- Groups of substances listed in Directive 96/22/EC, as further specified in Directive 96/23/EC: group A substances in Annex I to Directive 96/23/EC (A1, stilbenes, stilbene derivatives, their salts and esters; A2, antithyroid agents; A3, steroids; A4, resorcyclic acid lactones (including zeranol); A5, $\beta$-agonists; A6, substances in Table 2 in the Annex to Regulation (EU) No 37/2010

- Recombinant bovine somatotropin (rbST; Decision 1999/879/EC)

- Medicinal substances that are not listed in Table 1 in the Annex to Regulation (EU) No 37/2010

- Feed additives that are not (or no longer) authorised under Regulation (EC) No 1831/2003 


\section{Group I: Prohibited substances}

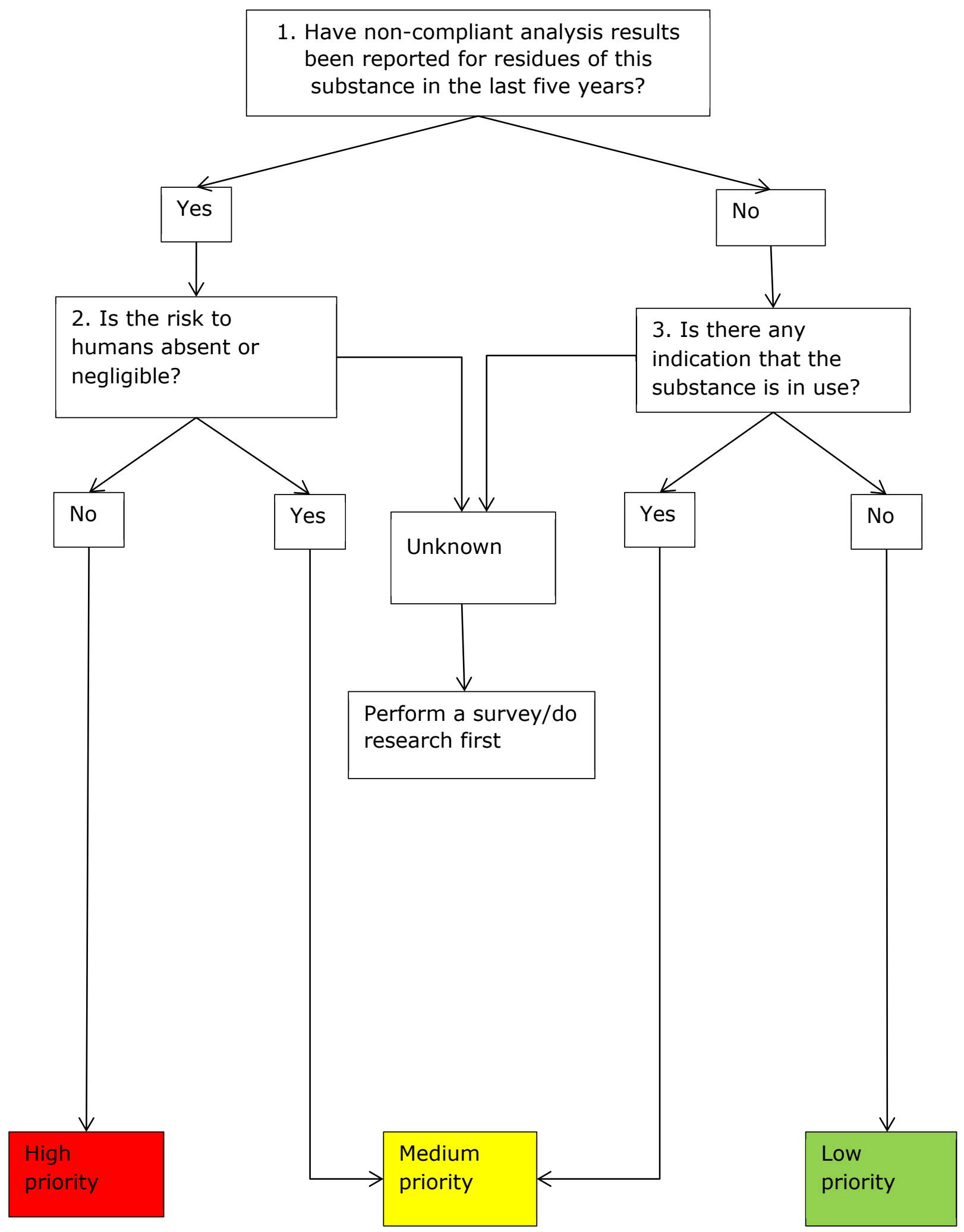

Figure 9 Decision tree for prohibited substances. 
Explanation of the questions for Group I, Prohibited substances (Figure 9):

Question 1: Have non-compliant results been reported for residues of this substance in the last five years?

- Yes: non-compliant analysis results were found during national monitoring and/or EU MS monitoring data and/or in RASFF. $\quad \rightarrow \quad$ QUESTION 2

- No: national monitoring and/or EU MS monitoring data and/or RASFF notifications have not revealed non-compliant analytical results, or the substance is not part of the monitoring programme.

$\rightarrow \quad$ QUESTION 3

Question 2: Is the risk to humans due to the presence of residues of this substance based on scientific evidence absent or negligible?

- Yes: It does not appear from EFSA or JECFA-publications or other scientific studies that the presence of residues of the substance(s) has a serious and/or irreversible adverse effect on consumer health.

$\rightarrow$ MEDIUM PRIORITY

- No: EFSA or JECFA publications or other scientific studies indicate that the substance(s) could have severe and/or irreversible adverse effects on consumers or their offspring (as in the case of genotoxic, carcinogenic and teratogenic endocrine disruptors). $\rightarrow$ HIGH PRIORITY

- Unknown: It is not clear whether the presence of residues of this/these substance(s) can have adverse effects on consumer health.

$\rightarrow \quad$ Do more research on the (negative) impact of residues of the prohibited substance.

If the answer to Question 1 is "No", this does not mean that the substances will not be found in animal products. It could be that the substances in question have not, or not sufficiently, been sought for. There is therefore a supplementary question on possible exposure of the animal:

Question 3: Is there an indication that the substances are being used?

- Yes: It appears from customs laboratory reports or other sources (e.g. information from other EU Member States, internet searches, or information from within the sector) that the substances are being used. $\rightarrow \quad$ MEDIUM PRIORITY

- No: No indications of use. $\rightarrow \quad$ LOW PRIORITY

- Unknown: there is no available information that could be used to determine whether the substance is being used.

$\rightarrow$ First perform a survey on the presence of the substance in this animal species.

\subsubsection{Decision tree for natural substances, contaminants and pesticide residues, Group II (Figure 10)}

This decision tree is employed for any substance that is not intentionally used in the primary production of livestock products, but which may have found its way into animal products via the environment, animal feed or drinking water. These are:

- The substances listed in Groups B3a (organochlorine compounds, including PCBs), B3b (organophosphorus compounds), B3c (chemical elements) and B3d (mycotoxins) in Annex I to Directive 96/23/EC

- Substances for which MLs have been set in animal products (e.g. dioxins)

- Substances for which indicative limits or action limits, etc. have been set

- Substances for which MRLs have been set in animal products (plant protection products and, possibly at some time in the future, biocides)

- Substances for which there are no (or not yet) legal limits in animal products but that are known to pose a possible risk to consumers.

Pesticides used in animals and included in Table 1 of the Annex to Regulation (EU) No 37/2010, for example certain insecticides, come under the 'permitted substances', which are run through decision tree III. The remaining pesticides can enter animal products through contaminated feed and/or the environment. This exposure route is similar to that of contaminants such as dioxins and heavy metals. Hence, these pesticides are dealt with in decision tree II. 


\section{Group II: Contaminants, natural substances and pesticide residues}

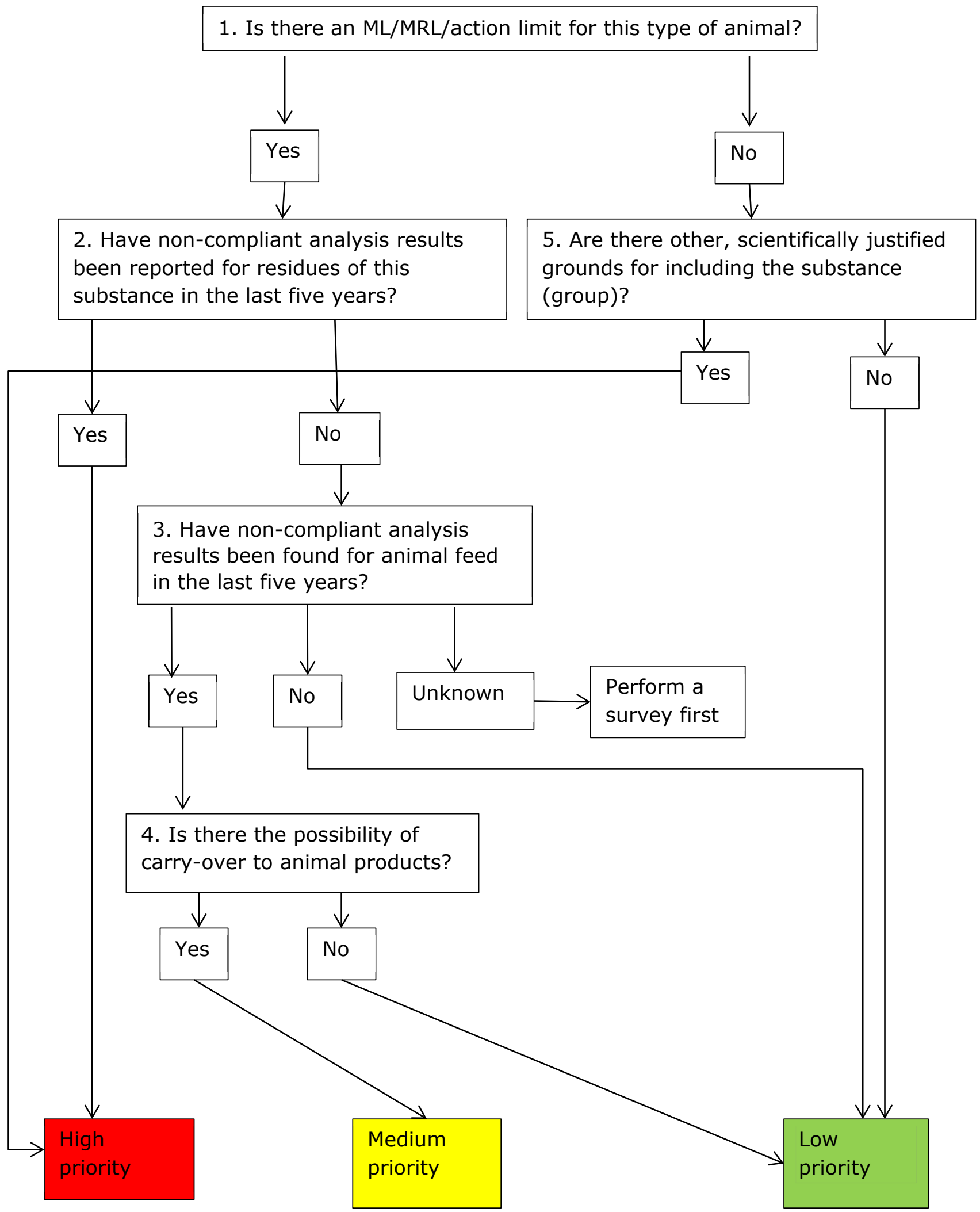

Figure 10 Decision tree for natural substances, contaminants and pesticide residues. 
Explanation of the questions for Group II, Contaminants, natural substances and pesticide residues Question 1: Is there an ML/MRL/action limit for the substance in question in organs/tissues from this animal species?

- Yes: the substance has an MRL, ML or action limit.

- No: the substance has no MRL, ML or action limit.

$\begin{array}{ll}\rightarrow & \text { QUESTION } 2 \\ & \text { QUESTION } 5\end{array}$

Question 2: Have non-compliant results been reported for this substance in the last five years?

- Yes: Non-compliant results were found during national monitoring and/or in EU MS monitoring data and/or in RASFF. $\quad \rightarrow \quad$ HIGH PRIORITY

- No: There were no non-compliant analytical results in national monitoring and/or in EU MS monitoring data and/or in RASFF notifications or the substance is not part of the monitoring programme. $\rightarrow$

QUESTION 3

If the Answer to Question 2 is "No", this does not mean that substances will not be found in animal products. It may be that the substance has not, or not sufficiently, been investigated. For this reason, there are supplementary questions about the potential exposure of the animal (QUESTIONS 3 and 4 ):

Question 3: Have non-compliant results been found for animal feed in the last five years?

- Yes: non-compliant results were found in national monitoring and/or in EU MS monitoring data and/or in RASFF notifications.

$\rightarrow \quad$ QUESTION 4

- No: there were no non-compliant results in national monitoring and/or in EU MS monitoring data and/or in RASFF notifications. $\quad \rightarrow \quad$ LOW PRIORITY

- Unknown: there are no/few data on the substance in feed and it is therefore also unclear whether or not it may occur in animals

$\rightarrow \quad$ First do a survey on the substance's presence in this type of animal.

Question 4: Is carry-over to animal products/edible parts possible?

- Yes: It is known from transfer studies (in the literature) or expert statements that substances that are found in feed can be found in animal products ( $>1 \%$ transfer).

$\rightarrow \quad$ MEDIUM PRIORITY

- No: There are no indications that transfer to animal products is possible or likely.

$\rightarrow \quad$ LOW PRIORITY

Question 5: Are there other, scientifically justified grounds for including the substance/group of substances in the NP Residues?
- Yes:
$\rightarrow$
HIGH PRIORITY

- EFSA opinions show that the ADI/TDI is exceeded by certain sections of the population or that the MOE is too low and that animal products make a significant contribution ( $\geq 5 \%$ );

- The Commission recommends monitoring the substance/group of substances in products from this animal species;

- EFSA recommends collecting more data on this substance in animal products;

- There are proposals for setting MLs for this substance/animal species/product;

- Scientific assessments have been carried out by other respected food authorities in the EU (BfR, ANSES, NVWA-BuRO FSA-UK, etc.) that point to the need to monitor risks to humans;

- The substance has been detected in the last five years in animal products in national and/or EU MS monitoring and there are reports of this substance in RASFF notifications.

- No: There are no substantiated reasons for including this substance/group of substances (e.g. on the basis of EFSA opinions, it does not appear that the ADI/TDI is exceeded by certain sections of the population, the MOE is high (> 10000 ) or animal products do not make a significant contribution to exposure $(<5 \%))$.

$\rightarrow \quad$ LOW PRIORITY

\subsubsection{Decision tree for authorised substances, Group III (Figure 11)}

A safety assessment must have been performed before authorised substances are allowed to be used. The authorisation of feed additives and setting of MRLs takes place at EU level. An application for authorisation of the active ingredients of veterinary drugs must be made at EU level; authorisation and the setting of MRLs for residues of the active substance are also decided on at that level. 
Veterinary medicinal products (veterinary drugs) in which the substances are included are registered at national level. The registration sets out instructions for use and withdrawal periods. The use of veterinary drugs in accordance with the rules has therefore been deemed safe. Therefore, when substances are found at a level above the MRL, they are given medium priority. An exception is made for antimicrobial substances that are essential for use in human therapy. Although residues of these substances do not present any danger for human use if the substance has been authorised and is used correctly, use of these substances can lead to resistance. The risk associated with use of these substances is accounted for in the decision tree and gives rise to a high priority.

There are cases where an active ingredient appears on the list of authorised substances, and its MRLS have been established, but no veterinary drug containing this active substance is registered in the Netherlands. A non-registered veterinary drug might have been registered in a neighbouring country and used in the Netherlands under the 'cascade' provisions. Moreover, in the case of imported meat in which residues of an EU-authorised substance are found, it is difficult to verify whether the use of the drug containing the substance has been authorised for that animal species in the country of origin. This decision tree is therefore based on authorised substances rather than on registered veterinary drugs in the Netherlands. The substances in question are the following:

- Substances listed in Table 1 of the Annex to Regulation (EU) No 37/2010 (including group B1 (antibacterial substances, including sulphonamides, quinolones) and Group B2 (other veterinary drugs) in Annex I to Directive 96/23/EC).

- Feed additives appearing in the list of authorised additives annexed to Regulation (EC) No 1831/2003 (EU Register of feed additives) that may be used in the EU in the feed of one or more types of farm animals.

- Residues of coccidiostats or histomonostats that find their way into animal products as a result of carry-over to non-target animal feed (Regulation (EC) No 124/2009). 
Group III: Authorised substances

1. Is the substance an essential antimicrobial substance for humans?

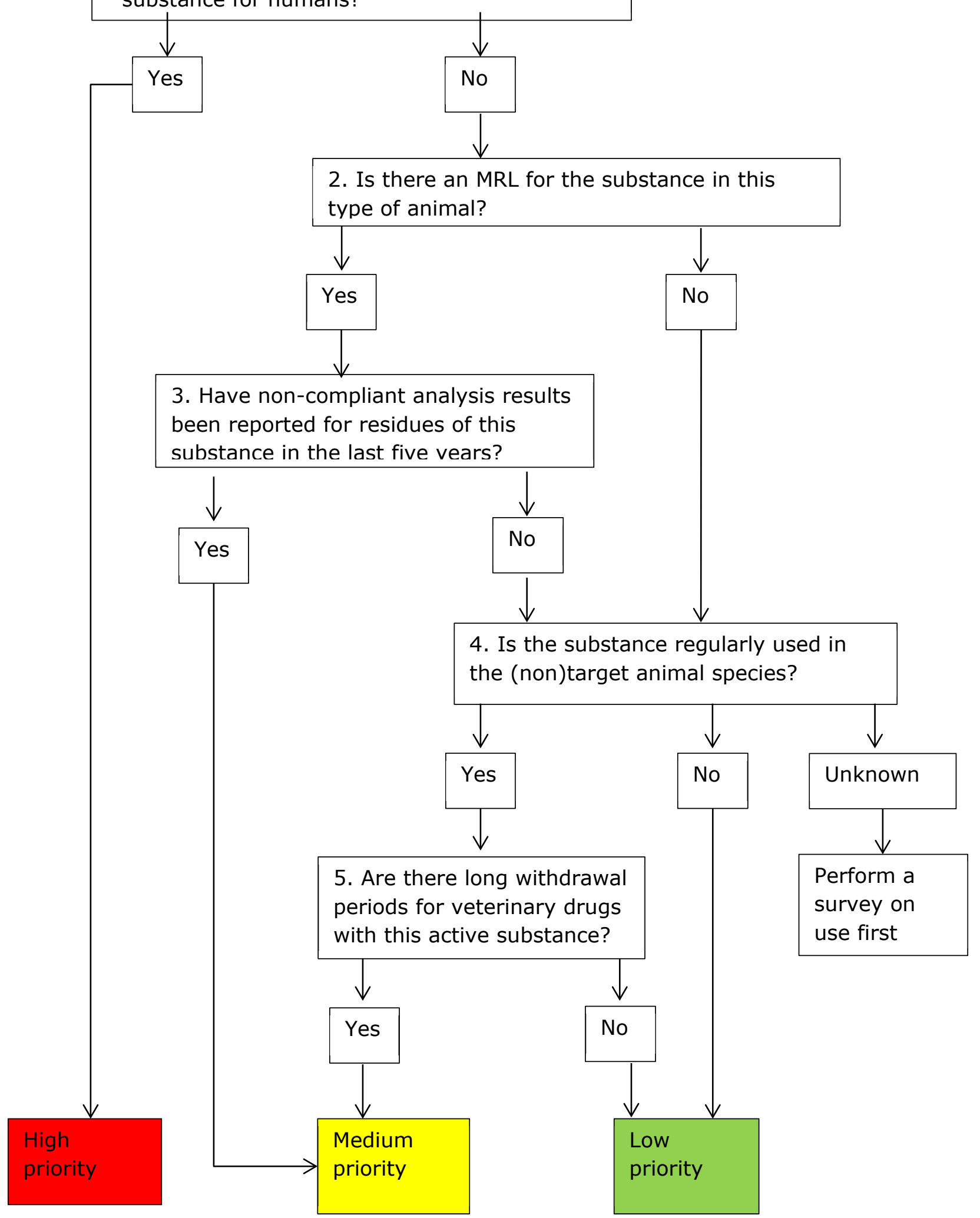

Figure 11 Decision tree for authorised active substances in veterinary drugs. 
Explanation of the questions for Group III, Authorised active substances in veterinary drugs

Question 1: Is the substance an essential antimicrobial substance for humans?

- Yes: the substance is a third-choice agent, such as $3^{\text {rd }}$ and $4^{\text {th }}$-generation cephalosporins, according to the guidelines issued by the WVAB (Dutch Working Party on Veterinary Antibiotic Policy) in 2015 or otherwise identified as essential for the treatment of bacterial infections in humans. $\quad \rightarrow$ HIGH PRIORITY

- No: the substance is a first or second-choice agents, such as $1^{\text {st }}$ - and $2^{\text {nd }}$-generation cephalosporins, according to the WVAB guidelines (2015) or otherwise considered non-essential for treatment of bacterial infections in humans (WVAB, 2015) $\rightarrow$ QUESTION 2

Question 2: Is there an MRL for the substance in this animal species?

- Yes: The substance has an MRL for this animal species. $\quad \rightarrow \quad$ QUESTION 3

- No: The substance has no MRL for this animal species (for example, the substance has an MRL for cattle, but not for goats). $\quad \rightarrow \quad$ QUESTION 4

Question 3: Have non-compliant results been reported in animal products in the last five years?

- Yes: Non-compliant results were reported via national monitoring and/or EU MS monitoring data and/or RASFF notifications. $\rightarrow \quad \rightarrow \quad$ MEDIUM PRIORITY

- No: no non-compliant results were found via national monitoring and/or EU MS monitoring data and/or RASFF notifications, or the substance is not part of the monitoring programme.

$\rightarrow \quad$ QUESTION 4

If the answer to Question 3 is "No", this does not mean that the substances will not be found in animal products. It may be that the substances have not, or not sufficiently, been sought for. There are therefore supplementary questions about potential exposure of the animal (QUESTIONS 4 and 5).

Question 4: Is the substance used regularly in the (non-)target species?

- Yes: According to information sources (SDa reports, KNMvD formularies, FIDIN data, statements by experts), veterinary drugs containing this active substance(s) are regularly used in this animal species and in group treatment.

QUESTION 5

- No: According to information sources (SDa reports, KNMvD formularies, FIDIN data, statements by experts), veterinary drugs containing this/these active substance(s) are not used regularly in this animal species, or are only used for individual treatment. $\quad \rightarrow \quad$ LOW PRIORITY

- Unknown: There is no information about the use of veterinary drugs containing this active substance(s) in this animal species.

$\rightarrow \quad$ Carry out a survey on use first.

Question 5: Are there fairly long withdrawal periods for veterinary drugs containing this/these active substance(s)?

- Yes: the most commonly used medicines containing these active substances have relatively long withdrawal periods ( $\geq 10$ days for red meat; Danaher et al., 2016), which means that it takes a long time for the residue concentrations in animal products to fall below their MRLs.

$\rightarrow \quad$ MEDIUM PRIORITY

- No: the most commonly used medicines containing these active substances have relatively short withdrawal periods (< 10 days for red meat; Danaher et al., 2016); the residue concentrations in animal products fall below their MRLs soon after the drug is administered for the last time.

\section{$\rightarrow \quad$ LOW PRIORITY}

\subsubsection{Testing the decision trees}

For a number of substances/groups of substances, the decision trees are used for pigs. For the evaluation of non-compliant test results, use was made of (a) monitoring at national level, (b) monitoring by EU Member States, and c) RASFF notifications. In order to answer the questions in the decision trees, the following data were used: the KAP database (2010 and 2011, but 2010 to 2014 in the case of dioxins), Commission monitoring reports for 2010-2014 pursuant to Directive 96/23/EC for the results for the Netherlands, EFSA monitoring reports for 2010-2014 pursuant to Directive 96/23/EC for the results in other Member States, and the RASFF database (2010-2014). 
The following substances were chosen for testing the decision trees: dienestrol, chloramphenicol and $17 \beta-19$-nortestosteron (Nandrolone) belonging to the decision tree for Group I, dioxins and dioxin-like PCBs, the flame retardant BDE-99, cadmium, DDT and glyphosate belonging to Group II, and the tetracyclines (doxycycline, oxytetracycline, tetracycline and chlortetracycline), colistin, levamisole, toltrazuril and apramycine to Group III. Tetracyclines are treated as one group of substances because their MRLs are similar.

\subsection{Test run of the decision tree for Group I, Prohibited substances \\ Question 1: Have non-compliant results been reported for residues of this substance in pigs in the last five years?}

\section{Dienestrol:}

Answer to Question 1 = NO: Non-compliant results have not been obtained in the Netherlands, nor in KAP or Commission reports or RASFF notifications.

\section{Chloramphenicol:}

Answer to Question 1 = YES: In the Netherlands, non-compliant results have not been obtained (neither in the KAP nor in Commission reports), but have been obtained in other EU Member States. The number of non-compliant results obtained in other EU Member States according to Commission reports are as follows: 6 in 2010, 1 in 2011, 10 in 2012, 5 in 2013, and 1 in 2014. Accordingly, no further searches of RASFF notifications were performed.

\section{7 $\beta$-19-nortesteron (Nandrolone):}

Answer to Question 1 = YES: non-compliant results have been obtained in the Netherlands (11 in 2010-2011 according to KAP and 9 in 2010, 2 in 2011, 14 in 2012, 11 in 2013 and 6 in 2014 according to Commission reports). A large share of the non-compliant results was found to be the result of misclassifications of the animal's sex (animals that had been identified as female turned out to be male; this hormone is naturally present in males). Other results remain unexplained, however. The results of other EU reports and RASFF notifications were not further examined.

\section{Question 2: Is the risk to humans due to the presence of residues of this substance based on scientific evidence absent or deemed negligible?}

\section{Chloramphenicol:}

Answer to Question 2 = NO: The EFSA concluded that an MRPL of $0.3 \mu \mathrm{g} / \mathrm{kg}$ of tissue can be used as the RPA (i.e. levels below $0.3 \mu \mathrm{g} / \mathrm{kg}$ do not endanger the consumer). The EFSA also concluded that the substance is genotoxic, that the mechanism of genotoxicity should be further examined, and that information on the carcinogenicity of chloramphenicol was lacking (EFSA, 2014). JECFA concludes that a safe level cannot be identified and that chloramphenicol should therefore not be used in foodproducing animals (JECFA, 2004). A risk cannot therefore be ruled out. Priority for inclusion in monitoring is $\mathrm{HIGH}$.

\section{7ß-19-nortesteron (Nandrolone):}

Answer to Question 2 = NOT KNOWN: Nandrolone is a very powerful anabolic androgenic steroid and is used illegally to promote growth and improve the feed conversion ratio. For nandrolone, the RCs are as follows: urine: $1 \mathrm{ppb}$; liver: $2 \mathrm{ppb}$; muscle: $1 \mathrm{ppb}$. This hormone is naturally present in male and cryptorche pigs, and often at levels that exceed the RCs (Poelmans et al., 2005). According to the EFSA, however, RCs would be too high to serve as the RPA (EFSA, 2013b). This means that, in toxicological terms, the current analytical limit does not provide adequate protection. However, no risk assessment has been performed on nandrolone. The outcome of the decision tree in this case is: More research is needed into the (adverse) effects of residues of the prohibited substance. 


\section{Question 3: Is there an indication that the substances are being used in pigs?}

Dienestrol:

Answer to Question 3 = YES. DES and HEX were found in pigs in 2014 and 2013 respectively. Therefore, it can be concluded that dienestrol might also be used. Priority for inclusion in monitoring is MEDIUM.

\subsection{Test run of the decision tree for Group II, Contaminants, natural substances and pesticide residues}

Question 1: Is there an ML/MRL/action limit for this substance in pig organs/tissue?

Dioxins and dioxin-like PCBs:

Answer to Question 1 = YES: Regulation (EC) No 1881/2006

BDE 99:

Answer to Question $1=$ NO.

Cadmium:

Answer to Question 1 = YES: Regulation (EC) No 1881/2006

DDT:

Answer to Question 1 = YES: Regulation (EC) No 396/2005

Glyphosate:

Answer to Question 1 = YES: Regulation (EC) No 396/2005.

\section{Question 2: Have non-compliant results been found in animal products in the last five years?}

Dioxins and dioxin-like PCBs:

Answer to Question 2 = YES: according to KAP, there has been one sample above the ML. Priority for inclusion in monitoring is $\mathrm{HIGH}$.

\section{Cadmium:}

Answer to Question 2 = YES: no non-compliances in kidneys (2010 and 2011) have been reported by KAP, and there were no RASFF notifications between 2010 and 2014, but according to the Commission reports there was one sample above the ML in 2012. Priority for inclusion in monitoring is $\mathrm{HIGH}$.

DDT:

Answer to Question 2 = NO: KAP doesn't contain data on DDT in pigs for 2010-2011; Commission reports show no non-compliances for 2010-2014, but EFSA reports 3.3\% of the samples from pigs contained DDT < MRL in 2010; in 2011 this was 2.4\%; no quantifiable levels were found in pig samples in 2012; in 2013, DDT levels < MRL were found in 1.6\% of pig samples; and in 2014, the substance was found in levels $<M R L$ in $1.3 \%$ of livers (of all types of animals).

Glyphosate:

Answer to Question 2 = Not known. There are no data in the KAP for glyphosate in pigs for 20102011, nor in Commission reports or RASFF notifications.

Question 3: Have non-compliant results been found for animal feed in the last five years?

$D D T$ :

For DDT and metabolites, the legal limits (MLs) have been laid down in Annex I to Directive 2002/32/EC. For feed materials and compound feeds (excluding fats and oils), there is an ML of $0.05 \mathrm{mg} / \mathrm{kg}$ and for fats and oils there is an $\mathrm{ML}$ of $0.5 \mathrm{mg} / \mathrm{kg}$ (in feed with a moisture content of $12 \%)$. 
Answer to Question 3 = YES: According to the most recent trend analysis for organochlorinated substances in feed (Adamse et al, 2014), DDT is still very rare in feed (found in 5 of the 5000 samples examined in the period 2001-2011), and consistently always < ML. However, according to RASFF, there were four notifications of DDT between 2010 and 2014 in feed imported from outside the EU.

Glyphosate:

MRLs were set for residues of glyphosate, but only for products that can be used as both food and feed. There are no legal limits for products used exclusively as animal feed and compound feed, etc. Answer to Question 3 = NO: A survey of the NVWA (2010-2015) shows no non-compliances. Priority for inclusion in monitoring is LOW.

Question 4: Is carry-over to animal products/edible parts possible?

DDT:

Answer to Question 4 = YES. DDT can accumulate in animal tissue, including porcine tissue (EFSA, 2006). Priority for inclusion in monitoring is MEDIUM.

\section{Question 5: Are there other (scientifically) justified reasons for including the substance/group of substances?}

BDE 99:

Answer to Question 5 = YES: EFSA concludes the following: 'For BDE-99 there is a potential health concern with respect to current dietary exposure' (EFSA, 2011b). Priority for inclusion in monitoring is $\mathrm{HIGH}$.

\subsection{Test run of decision tree for Group III, Authorised substances}

\section{Question 1: Is the substance an essential antimicrobial substance for humans?}

\section{Colistin:}

Answer to Question 1 = YES. Colistin is an essential antimicrobial agent. The WVAB recommends that this substance be phased out (WVAB, 2015). Priority for inclusion in monitoring is $\mathrm{HIGH}$.

Tetracyclines (chlortetracycline, oxytetracycline, tetracycline, doxycycline):

Answer to Question 1 = NO: Tetracyclines are first-choice agents (WVAB, 2015).

Levamisole:

Answer to Question 1 = NO: Levamisole is an antiparasitic agent

Apramycine:

Answer to Question 1 = NO: Apramycine is a second-choice agent (WVAB, 2015).

Toltrazuril:

Answer to Question 1 = NO: Toltrazuril is a coccidiostat.

Question 2: Is there an MRL for the substance in pigs?

Tetracyclines (chlortetracycline, oxytetracycline, tetracycline, doxycycline):

Answer to Question 2 = YES: Regulation (EU) No 37/2010

Levamisole:

Answer to Question 2 = YES: Regulation (EU) No 37/2010

Apramycine:

Answer to Question 2 is YES: Regulation (EU) No 37/2010 
Toltrazuril:

Answer to Question 2 = YES: Regulation (EU) No 37/2010

\section{Question 3: Have non-compliant results been obtained in pigs in the last five years?}

Tetracyclines (chlortetracycline (CTC), doxycycline (dox), oxytetracycline OTC) and tetracycline (TC)): Answer to Question 3 = YES: According to KAP, eight non-compliances for DOX and seven for OTC in 2010-2011; according to Commission reports, three non-compliances for OTC and six for DOX in 2010; four for OTC and two for DOX in 2011; one for DOX in 2012; two for OTC and one for DOX in 2013; and two non-compliances for OTC and one for DOX in 2014 (in total, 11 non-compliances for OTC and 11 for DOX). Priority for inclusion in monitoring is MEDIUM.

\section{Levamisole:}

Answer to Question 3 = YES: KAP contains four non-compliances in 2010; The Commission reports showed four non-compliances in 2010, none in 2011, none in 2012, two in 2013 and none in 2014; EFSA reported four non-compliances in 2010, none in 2011, none in 2012, one in 2013 and none in 2014. Priority for inclusion in monitoring is MEDIUM.

\section{Apramycine:}

Answer to Question 3 = NO: In the Netherlands, no non-compliant results were found in KAP and Commission reports, nor has the substance been reported as non-compliant in other European countries (EFSA reports) or RASFF notifications.

\section{Toltrazuril:}

Answer to Question 3 = NO: In the Netherlands, no non-compliant results were found in KAP or Commission reports, nor has the substance been reported as non-compliant in other European countries (EFSA Reports) or in RASFF notifications.

\section{Question 4: Is the substance used regularly in the (non-)target species?}

Apramycine:

Answer to Question $4=$ NO: Apramycine belongs to the aminoglycosides. According to the SDa, they are not used in pigs (SdA, 2016b). Priority for inclusion in monitoring is LOW.

Toltrazuril:

Answer to Question 4 = YES: Toltrazuril is most commonly used in pigs with coccidiosis.

\section{Question 5. Do agents containing this active substance(s) have relatively long withdrawal periods?}

Toltrazuril:

Answer to Question 5 = YES: Toltrazuril has a withdrawal period of 77 days. Priority for inclusion in monitoring is MEDIUM.

\subsubsection{Conclusions in the light of the tests}

Table 5 (below) shows the classification of the tested substances using the decision trees. The table shows that the decision trees make it possible to attribute low, medium or high monitoring priority to the substances. Where no or insufficient information is available, it is indicated that more research is needed. By testing the decision trees for a number of substances, it was possible to make the questions more nuanced and adapt the decision trees accordingly, resulting in the decision trees as they appear in Figures 9 to 11. In order to run substances through the decision trees satisfactorily, it is essential that all the necessary information is available. For the Netherlands, the results of national monitoring were used, as set out in Commission reports and the KAP database. Unfortunately, the KAP database only contains data for the period up to 2011. More recent data are necessary in order to make reliable use of the decision trees for the Netherlands. 
Table 5 Test results of the decision trees.

\begin{tabular}{|c|c|c|c|}
\hline Decision tree & Group & Substance & Classification \\
\hline I & $\mathrm{A} 1$ & Dienestrol & Medium priority \\
\hline I & A3 & Nandrolone & More research needed \\
\hline II & B3a & Dioxins and dioxin-like PCBs & High priority \\
\hline II & B3a & DDT & Medium priority \\
\hline II & - & BDE-99 & High priority \\
\hline II & - & Glyphosate & Low priority \\
\hline III & B1 & $\begin{array}{l}\text { (Tetracyclines, oxytetracycline, tetracycline, doxycycline and } \\
\text { chlortetracycline) }\end{array}$ & Medium priority \\
\hline III & $\mathrm{B} 2 \mathrm{a}$ & Toltrazuril & Medium priority \\
\hline
\end{tabular}

\subsubsection{Determining the matrix}

Once the decision trees described in 3.3.2 are used to determine which substances should be monitored in what types of animal, it then needs to be decided what the most appropriate matrix is and where in the supply chain (on the farm or in the slaughterhouse) sampling should be done. This depends, among other factors, on the metabolism of a substance in combination with the most likely stage of administration (the best chance of detecting residues) and practical considerations. Meat and kidneys can only be sampled in the slaughterhouse. Sampling at the farm has traditionally been limited mainly to urine samples. However, research is currently being done into the possibility of using analyses of feathers to detect instances where the use of antibiotics has not been administered properly (Berendsen et al., 2013; Jansen, Bolck \& Berendsen, 2016) and the possibility of detecting prohibited substances in bristles (Becue et al., 2011). This approach would increase the chances of detecting illegal use and prohibited substances because residues of numerous substances remain for longer in hair or bristles and feathers than in meat or urine. The stage at which sampling is done is important. For example, antibiotics could be administered as herd treatment, especially to young animals. Therefore, hair, bristles and feathers could best be collected from young animals. Hormones and other illegal substances are usually administered later in the animal's life, and it therefore makes sense for samples to be collected at a later stage. Taking hair or bristles from older animals, however, is often more difficult. In addition to animal-related matrices, it also makes sense to take environmental samples, e.g. from drinking water, feed and manure, in order to detect the illegal use of prohibited substances or the incorrect use of antibiotics. The use of rapid, on-site detection methods can help to more effectively target suspect pens or animals requiring further investigation.

Another interesting matrix for the detection of prohibited substances is saliva, which is already used for detecting the presence of steroids (A3) etc. in humans (Gröschl, 2008) but which is hardly used at all for detection in animals. The Flemish Research Institute for Agriculture, Fisheries and Food (ILVO) is performing a study of antibiotic residues in pig saliva. Prohibited substances are sometimes detected in blood serum. Blood sampling on the farm is not permitted, however, as it is falls within the scope of the Experiments on Animals Act ('Wet op de dierproeven'). A possible way forward on this issue is the development of a methodology similar to the 'heel prick test' performed on babies. This method is regarded as non-invasive and could in future be used for sampling on the farm, which would significantly increase the chance of detecting certain illegal substances. More research is needed into the reliability and sensitivity of analyses of hair, bristles, feathers and saliva and the heel prick method before they can be validated and applied.

Table 6, which was compiled in consultation with experts at RIKILT and NVWA, shows which matrix has the best chance of detecting residues of each group of substances in red meat. 
Table 6 Recommended matrix for detecting the presence of various groups of substances in red meat at the farm and slaughterhouse stages.

\begin{tabular}{|c|c|c|}
\hline \multirow[t]{2}{*}{ Group of substances } & \multicolumn{2}{|l|}{ Recommended matrix for red meat } \\
\hline & Sampling on the farm & $\begin{array}{l}\text { Sampling } \\
\text { in the slaughterhouse }\end{array}$ \\
\hline $\begin{array}{l}\text { Antibiotics } \\
\text { (group B1) }\end{array}$ & $\begin{array}{l}\text { For detecting incorrect record keeping of } \\
\text { antibiotics use or for detecting the use of } \\
\text { unauthorised agents: urine, environmental } \\
\text { samples (feed, drinking water, manure) }{ }^{1} \text {, hair or } \\
\text { bristles }^{1} \text {, saliva }^{1} \text {, }\end{array}$ & $\begin{array}{l}\text { For detecting MRL infringements: meat, } \\
\text { kidneys }\end{array}$ \\
\hline $\begin{array}{l}\text { Other veterinary drugs } \\
\text { (group B2) }\end{array}$ & $\begin{array}{l}\text { For detecting incorrect records keeping of other } \\
\text { veterinary drugs use or for detecting the use of } \\
\text { unauthorised agents: urine, environmental } \\
\text { samples (feed, drinking water, manure) }{ }^{1} \text {, hair or } \\
\text { bristle }^{1} \text {, saliva }{ }^{1}\end{array}$ & $\begin{array}{l}\text { For detecting MRL infringements: meat, } \\
\text { kidneys (tranquilisers), liver } \\
\text { (anthelmintics), blood plasma } \\
\text { (nitroimidazoles)) }\end{array}$ \\
\hline $\begin{array}{l}\text { Pesticides } \\
\text { (Group B3a, B3b) }\end{array}$ & Feed & $\begin{array}{l}\text { Fat (lipophilic substances), meat, liver or } \\
\text { kidney (other substances, particularly } \\
\text { those which are found in feed) }\end{array}$ \\
\hline $\begin{array}{l}\text { Heavy metals } \\
\text { (Group B3c) }\end{array}$ & Feed & Meat, kidneys, liver \\
\hline Mycotoxins (group B3d) & Feed & \\
\hline
\end{tabular}

\subsubsection{The heel prick method for analysing steroid esters}

This project represented the first step towards the possible use of the heel prick method as a means of detecting the illegal use of steroid esters on the farm. Steroid profiling is currently used to screen urine samples, and the results for suspect samples are confirmed using GC-C-IRMS. However, the demonstration of intact steroid esters in blood serum or plasma also provides direct evidence of exogenous administration. Currently, $1 \mathrm{ml}$ of blood is collected from suspect animals for monitoring purposes (see Figure 12). The purpose of this study was to apply the current method of measuring steroid esters in blood/blood serum to a Dry Blood Spot (DBS) analysis method and to determine whether it is feasible to perform the analysis using these small amounts of blood, which can be collected on the farm.

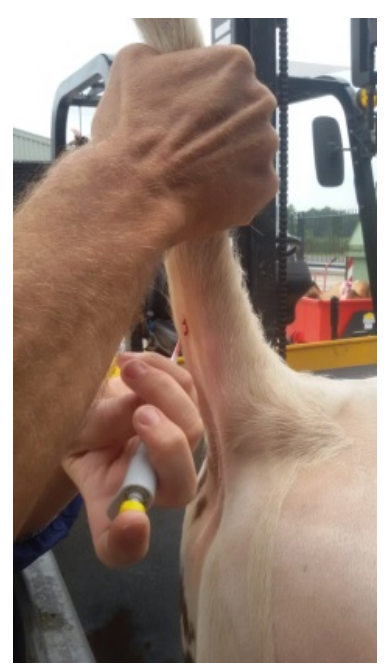

Figure 12 Collecting a drop of blood from a cow. 
Firstly, a suitable LC-MS/MS method was developed for analysing sustanon steroid esters, as described in section 2.4. The Dry Blood Spot Autosampler (DBSA) was then connected to the LC-MS system. The components should be derivated with methoxyamine (MOX) so as to obtain the lowest possible detection limit. In the first step, derivatisation was performed in the conventional manner, by collecting eluate, vaporising it in a vial and then derivatising it. $15 \mu \mathrm{l}$ of the derivatisation extract was placed on a DBS card and analysed using DBSA-LC-MS/MS. It was found that the derivatised steroid esters could be satisfactorily analysed using this method (see Figure 13).

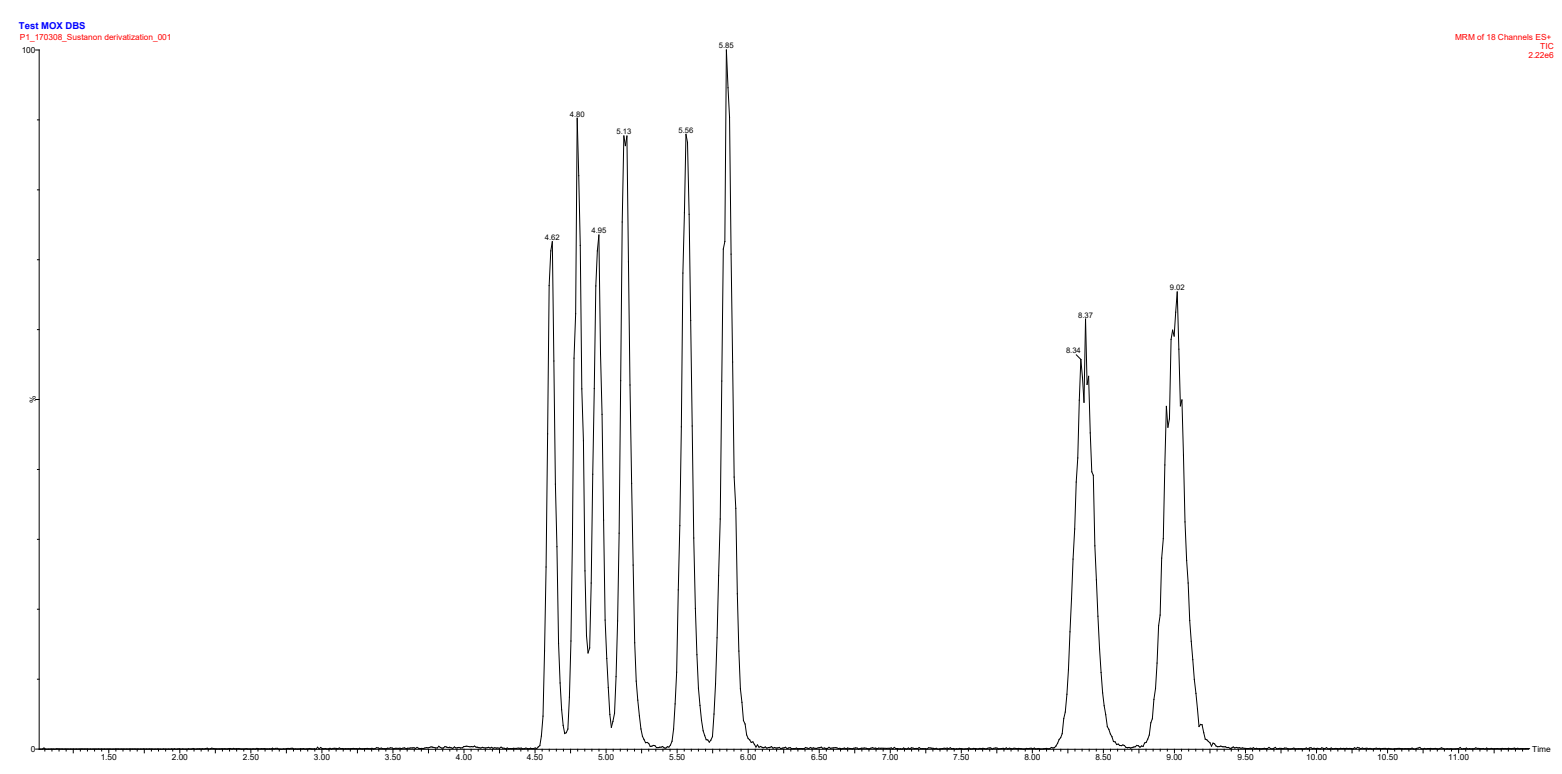

Figure 13 Total ion current chromatogram of a DBSA-LC-MS/MS analysis showing the separate peaks of 4 mox-steroid ester derivatives in solution.

In order to make the method genuinely suitable and efficient for use in practice, derivatisation should be done on the DBS cards. Several variations of the derivatisation stages were tested: with the blood drop dried and not dried before the derivatisation reagent is applied, various derivatisation temperatures and duration for heating the DBS cards, the concentration of the derivatisation reagent and the method used to apply it (in drops or using a spray). It was eventually decided to perform the derivatisation as follows: the blood was first enriched with a sustanon solution so as to obtain a concentration of $100 \mu \mathrm{g} / \mathrm{L}$. $15 \mu \mathrm{l}$ of this solution was applied to the DBS card using a pipette, and the card was then left to dry at room temperature for at least 60 minutes. $10 \mu 500 \mathrm{mM}$ of methoxyamine solution was then applied, after which the card was heated for 5 minutes at $80^{\circ} \mathrm{C}$. This procedure was repeated, with the card being heated for 60 minutes at $80^{\circ} \mathrm{C}$. The card was placed in the DBSA, and the DBSA-LC-MS/MS analysis was then performed.

After the procedure was optimised, it was possible to perform derivatisation on the DBS card. Figure 14 shows a chromatogram of a DBSA-LC-MS/MS analysis of a blood sample. 


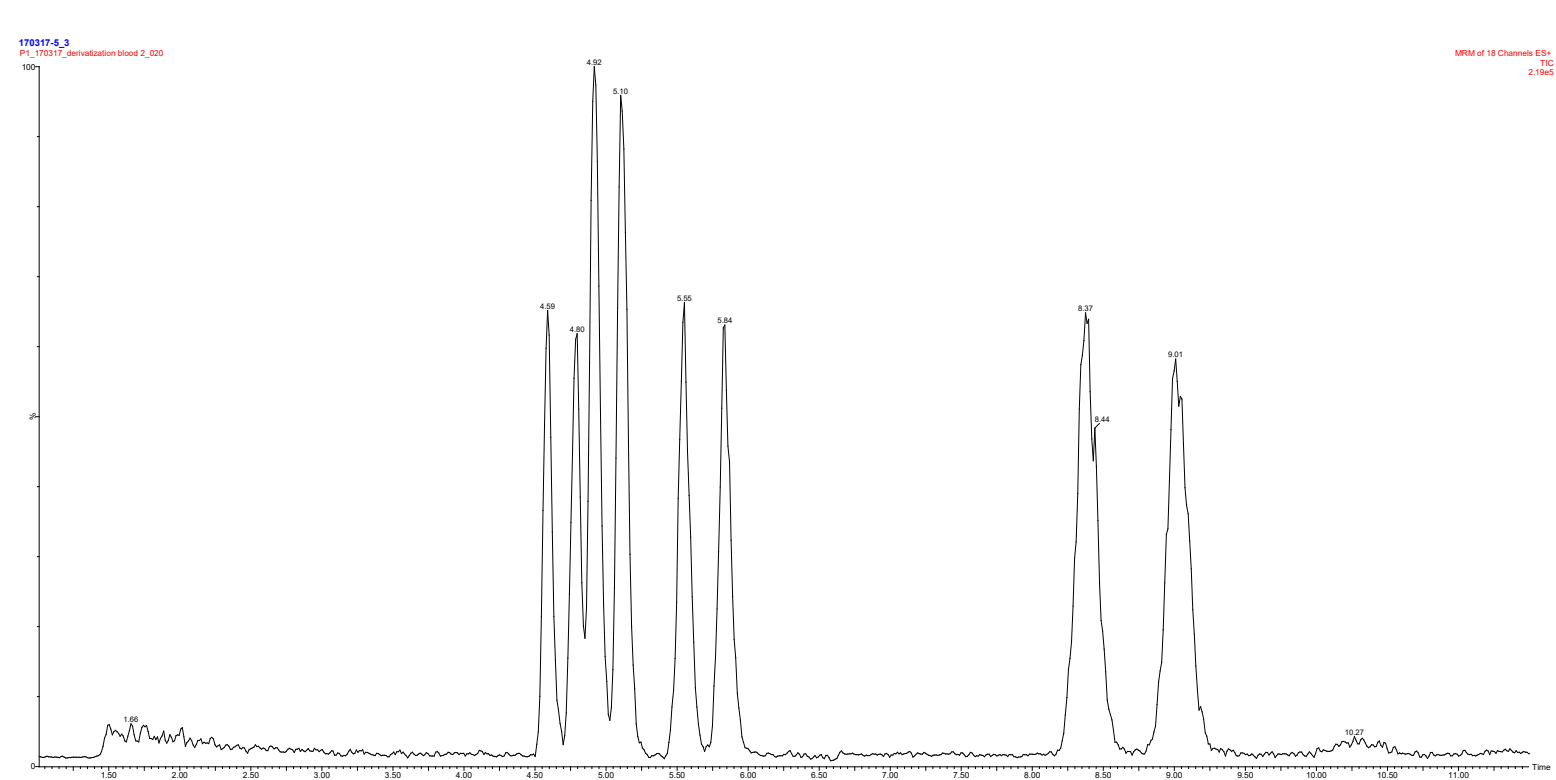

Figure 14 Total ion current chromatogram of a DBSA-LC-MS/MS analysis showing the various peaks of 4 mox-steroid ester derivatives in blood.

It can be concluded that the heel prick method works as a means of detecting steroid esters. Derivatisation on the DBS card also works, which means that an analytical method is available which requires minimal pre-processing of the samples. The method does, however, need to be further improved by using more sensitive columns with a different LC-MS system, so that the sensitivity, and therefore the LOD, can be lowered. Once this has been achieved, an efficient, effective and noninvasive method will be available for monitoring the illegal use of hormones on the farm.

\subsection{Efficient monitoring}

Efficient monitoring means obtaining as much information as possible at the lowest possible cost. This can be achieved by pooling samples to form a composite sample, thereby reducing the number of analyses that are necessary, or by developing new methods allowing the broadest possible spectrum of substances to be analysed. For example, an increasing number of multi-methods are used, which can measure a wide range of substances. Work is also being done to develop a single method that can measure various groups of substances, for example measuring pesticides and antibiotics using LC-MS. The challenge here is obtaining a sufficiently low detection limit for the various substances/groups of substances. A further improvement in efficiency involves sampling methods. In order to increase the chance of detection, it is important to trace suspect animals and/or farmers. Relevant strategies have been developed by NVWA Monitoring ('NVWA Toezicht'). This topic is not further developed in the present report; we focus here mainly on the choice of groups of substances, types of animal and matrices.

\subsubsection{Pooling of samples}

By combining samples to form composite sample, fewer analyses are needed. This frees up budget resources for performing additional analyses and/or extending the package of chemical analyses so that other substances can be analysed and/or broader screening performed. The disadvantage of pooling of samples is that dilution can cause positive samples to be missed, which gives rise to false negatives (Patil, 1995). The question is therefore what the optimum number of samples in a composite sample is if positive samples are not to be overlooked. If the LOD is close to the legal limit or the RC, the analysis of composite samples is less useful. A further condition for pooling is that the samples can be satisfactorily homogenised and that equal volumes can be combined, which is not necessarily the case in every matrix. Hair or bristles, for example, are less suitable because they can only be pooled after hair extraction. Hair or bristle extraction is a protracted process, therefore subsequent pooling will not save time. For some substances, broad screening is used (e.g. for 
antibiotics in group B1), at a level near to the MRL, and pooling is therefore not an option. The same applies to substances that are regularly detected because, when a pool is found to be suspect, all the individual samples still need to be analysed separately.

\subsubsection{Theoretical approach}

In order to determine whether it is effective to combine samples in a pool, calculations are performed with data from the KAP database. The data chosen for this purpose are urine samples from cattle and pigs. Groups of substances that could lend themselves for pooling for analytical purposes are $\beta$-agonists (Group A5) and steroids (A3), because these substances are found in urine, which is a good matrix for pooling. For these substances, moreover, there is a margin between the statutory limit and the detection limit, which allows pooling. However, for $\beta$-agonists there were few, if any, positives in KAP database, which made calculations for this group of substances difficult. It was therefore decided to carry out the calculations for steroids (Group A3).

The total number of samples to be analysed can be calculated by determining the number of composite samples and the number of repeat tests where a composite sample is positive ( $>$ RC). If a composite sample is positive, all samples have to be analysed individually. The total number of samples to be analysed is calculated as follows (where $n$ is the number of samples in a composite sample):

- number of composite samples: total number of actual samples/n

- number of repeat tests: number of samples with concentration: $C>R C / n$

- total number of samples: number of composite samples + number of repeat tests * $n$

It is assumed here that random samples are pooled, which may be positive or negative. Table 7 shows a sample calculation based on the KAP data for zearalenone, where 136 samples were $>$ RC. The total number of analyses is calculated for various values of $n(1 \ldots 6)$. If $n=1$, the number of composite samples corresponds to the number of individual samples and 1878 analyses are required. If 2 samples are combined $(n=2)$, there are 939 composite samples. Statistical calculations show that 131 positive samples can be expected, from which individual samples will need to be retested. This brings the total number of analyses to: $939+2 * 131=1201$. In the case of zearalenone, $n_{\max }$ (RC/LOD) is 6 . In theory, therefore, six samples can be combined to form a composite pool. Table 7, however, shows that the optimum number of samples to be combined in this case is 5 . On the basis of KAP data, it has been calculated that if 6 samples are combined to form a composite sample, 96 composite samples will be positive. These 96 composite samples must all be analysed individually. This brings the total number of analyses to: $313+6 * 96=889$. If $n=5$, the minimum number of analyses in this case is achieved, which is 870. It is therefore apparent that, if there is a relatively large number of suspect samples, numerous repeat tests will be required. The total number of analyses at $n_{\max }$ is then higher than if a smaller number of samples are combined to form a composite sample.

Table 7 Total number of composite samples and analyses with various values of $k$ (number of samples in a composite sample) for zearalenone in bovine urine.

\begin{tabular}{|c|c|c|c|}
\hline$n^{1}$ & Number of samples & $\begin{array}{l}\text { Number of positive } \\
\text { composite samples }\end{array}$ & Total number of analyses \\
\hline 1 & 1878 & 136 & 1878 \\
\hline 3 & 626 & 119 & 983 \\
\hline 4 & 469 & 104 & 885 \\
\hline 6 & 313 & 96 & 889 \\
\hline
\end{tabular}


Table 8 provides an overview of the optimum number of samples $\left(n_{\text {opt }}\right)$ that can be combined in a composite sample for all steroids for which information was available in KAP for the period from 2005 to 2014. This optimum number could only be calculated if positives were present in the database, because then the likelihood of a positive sample, and consequently the number of repeat tests, could be calculated. The RC and the LOD are also shown in Table 8. This makes it possible to calculate the maximum number of samples to be combined $\left(n_{\max }\right)$. The table also shows the current number of individual samples in the KAP database, the optimum number of samples to be combined and the number of analyses if samples are indeed pooled. It is assumed that false negatives are not accepted ( $100 \%$ confidence that all positives ( $>$ RC) are found). Where a lower percentage (e.g. $95 \%$ ) is accepted, some samples > RC will be missed (for example, in 5\% of the samples) and the number of positive samples is likely to be lower, and therefore also the number of repeat tests. More samples can then be combined.

Table $8 \quad$ Number of samples in pooled urine samples for steroid testing.

\begin{tabular}{|c|c|c|c|c|c|c|}
\hline Substance & RC ( $\mu g / I)$ & $\begin{array}{c}\text { LOD } \\
(\mu \mathrm{g} / \mathrm{I})\end{array}$ & $\begin{array}{l}\text { Number of } \\
\text { individual } \\
\text { samples in } \\
\text { KAP }\end{array}$ & $n_{\max }{ }^{1}$ & $n_{o p t^{2}}$ & $\begin{array}{c}\text { Number of } \\
\text { samples to be } \\
\text { analysed when } \\
\text { pooling }{ }^{3}\end{array}$ \\
\hline \multicolumn{7}{|l|}{ Calves and bovine animals } \\
\hline 4-Chloro-androst-4-ene-3,17-dion & 2 & 0.50 & 415 & 4 & -4 & - \\
\hline a-Nortestosteron & 1 & 0.50 & 7104 & 2 & 2 & 3812 \\
\hline a-Trenbolon & 2 & 0.50 & 3182 & 4 & -4 & - \\
\hline b-Boldenon & 1 & 0.25 & 7002 & 4 & $-{ }^{4}$ & - \\
\hline Dienestrol & 2 & 0.25 & 7104 & 8 & -4 & - \\
\hline Diethylstilboestrol & 1 & 0.25 & 7104 & 4 & -4 & - \\
\hline Methylboldenon & - & 0.50 & 7104 & & -4 & - \\
\hline Methyltestosterone & 2 & 0.50 & 7104 & 4 & -4 & - \\
\hline Nortestosteron & 1 & 0.50 & 7104 & 2 & 2 & 3558 \\
\hline Oestradiol & - & 0.50 & 5519 & & -4 & - \\
\hline Zearalanon & 2 & 0.30 & 2369 & 6 & 6 & 394 \\
\hline Zearalenone & 2 & 0.30 & 1878 & 6 & 5 & 870 \\
\hline \multicolumn{7}{|l|}{ Pigs } \\
\hline B-Nortestosteron & 1 & 0.50 & 2507 & 2 & 2 & 1253 \\
\hline B-Trenbolon & 2 & 0.50 & 874 & 4 & $-{ }^{4}$ & - \\
\hline Methyltestosterone & 2 & 0.50 & 2507 & 4 & -4 & - \\
\hline Nortestosteron & 1 & 0.50 & 2507 & 2 & 2 & 1835 \\
\hline Oestradiol & - & 0.50 & 1297 & & $-{ }^{4}$ & - \\
\hline Zearalanon & 2 & 1.00 & 676 & 2 & $-{ }^{4}$ & - \\
\hline Zearalenone & 2 & 1.00 & 494 & 2 & 2 & 475 \\
\hline \multicolumn{7}{|c|}{$1 \mathrm{n}_{\max }$ Maximum number of samples to be pooled to form one composite sample (= RC/LOD). } \\
\hline \multicolumn{7}{|c|}{$2 \mathrm{n}_{\mathrm{opt}}$ : Calculated optimum number of samples that can be combined to form one composite sample. } \\
\hline \multicolumn{7}{|c|}{3 Number of composite samples plus number of repeat tests on individual samples. } \\
\hline \multicolumn{7}{|c|}{$4 \mathrm{n}_{\mathrm{opt}}$ could not be determined, either because there is no RC or because there are no positive samples in th } \\
\hline
\end{tabular}

Table 8 shows that there is one substance for which the optimum number of samples that can be pooled to form a composite sample is six (zearalanon in calves and bovine animals). In practice, however, multi-methods are used, which involves measuring several substances simultaneously. The maximum number of substances that can be combined with these methods depends on the substance 
with the lowest value of $n$. In the case of zearalenone, although six samples could be combined to form a composite sample, it is part of a multi-method using LC-MS/MS. This method is also used to measure, for example, a-nortestosteron, for which a maximum of two samples can be combined (see Table 8). This means in practice that up to two samples can be combined to form a composite sample for these analyses.

\subsubsection{Pool experiments}

In the previous section, calculations were carried out with steroids to investigate whether the pooling of samples was theoretically possible. Experiments were then conducted to determine the extent to which, in practice, it is possible to combine samples. These experiments were carried out for the $\beta$-agonist group of substances because they are easy to measure (since, unlike steroids, they are not naturally present) and because their RCs vary (from 0.2 to $10 \mathrm{ppb}$ ). The aim of the experiment was to determine the maximum number of samples that can be combined to form a composite sample and to investigate the effect of the matrix.

For this purpose, two experiments were performed on $\beta$-agonists in cattle urine. In the first experiment, blank urine was enriched with $\beta$-agonists, as described in 2.6. The samples were then diluted with the same urine to determine whether one positive sample still could be found in a composite sample. In the second experiment, enriched samples were diluted with various urine samples. This experiment most closely approximates reality because, in practice, samples from various cows will be combined. The experiments were conducted as described in point 2.6 and Annex 3, The results show that most of the substances concerned can be found when diluted 5 times (Table 9). Some substances interacted with the matrix: with diluted substances, the peak of the substance coincided with the peaks of the matrix, making it impossible to determine the concentration. The substance did, however, have a visible effect on the chromatogram. It is therefore reasonable to assume that the substance is present. This then has to be confirmed by an analysis of single samples. In the first experiment, in which the same urine was used for dilution, this effect was visible for five substances: clenproperol, cimaterol, salmeterol, clenhexyl and terbulatine. These substances could therefore not be diluted 5 times.

In the second experiment, the sample was diluted using different urines. In this experiment, only three substances could not be diluted 5 times: clenproperol, cimaterol and clenhexyl. These substances could still be detected at a maximum dilution of 3 times, 2 times and 3 times respectively (see Table 9). In the case of salmeterol and terbutaline, the distorting effect of urine 1 was mitigated because of the addition of four other urine samples. As a result, these substances could still be detected in experiment 2 when diluted 5 times. 
Table 9 Optimum number of samples that can be pooled for the purpose of demonstrating the Recommended Concentration ( $R C$ ) where blank samples from the same cow are pooled (pool experiment 1) and where blank samples from several cows are pooled (pool experiment 2).

\begin{tabular}{|c|c|c|c|}
\hline Component & $\mathbf{R C}$ & $\mathbf{n}_{\max }$ (Pool experiment 1) & $\mathbf{n}_{\max }$ (Pool experiment 2) \\
\hline Clenbuterol & $0.2 \mu \mathrm{g} / \mathrm{l}$ & 5 & 5 \\
\hline Broombuterol & $0.2 \mu \mathrm{g} / \mathrm{l}$ & 5 & 5 \\
\hline Mapenterol & $0.2 \mu \mathrm{g} / \mathrm{l}$ & 5 & 5 \\
\hline Tulobuterol & $0.2 \mu \mathrm{g} / \mathrm{l}$ & 5 & 5 \\
\hline Hydroxymethylclenbuterol & $0.2 \mu \mathrm{g} / \mathrm{l}$ & 5 & 5 \\
\hline Clenpenterol & $0.5 \mu \mathrm{g} / \mathrm{l}$ & 5 & 5 \\
\hline Clenproperol & $0.5 \mu \mathrm{g} / \mathrm{l}$ & 3 & 3 \\
\hline Cimaterol & $0.5 \mu \mathrm{g} / \mathrm{l}$ & 2 & 2 \\
\hline Ractopamine & $1.0 \mu \mathrm{g} / \mathrm{l}$ & 5 & 5 \\
\hline Clencyclohexerol & $1.0 \mu \mathrm{g} / \mathrm{l}$ & 5 & 5 \\
\hline Salbutamol & $1.0 \mu \mathrm{g} / \mathrm{l}$ & 5 & 5 \\
\hline Salmeterol & $1.0 \mu \mathrm{g} / \mathrm{l}$ & 4 & 5 \\
\hline Zilpaterol & $1.0 \mu \mathrm{g} / \mathrm{l}$ & 5 & 5 \\
\hline Fenoterol & $1.0 \mu \mathrm{g} / \mathrm{l}$ & 5 & 5 \\
\hline Clenhexyl & $1.0 \mu \mathrm{g} / \mathrm{l}$ & 3 & 3 \\
\hline Procaterol & $1.0 \mu \mathrm{g} / \mathrm{l}$ & 5 & 5 \\
\hline Carbuterol & $1.0 \mu \mathrm{g} / \mathrm{l}$ & 5 & 5 \\
\hline
\end{tabular}

Pool experiments confirm the results of the calculations described in 3.3.1.1: pooling of up to $5 x$ is possible for a number of substances, but inevitably some substances will be missed. If it is considered necessary to show the complete list of substances, the maximum number of samples that can be aggregated is two.

Analytical techniques, however, are constantly being improved and optimised, allowing samples to be analysed not only more quickly, but also with greater sensitivity (Dorne et al., 2009). If the detection limit can be reduced further, it will be possible to pool more samples to form one composite sample for analysis purposes. Nevertheless, the most time-consuming step is usually sample pre-processing, because the matrices can be extremely complicated, which means that various steps are necessary in order to extract the required components (Dorne et al., 2009). In practice, moreover, the more sensitive methods are liable to produce more noise, with several peaks being visible. This noise might have a distorting effect on the tested substances. The results shown in Table 9 were obtained using the equipment currently available to RIKILT. If other is equipment used, or if more sensitive methods are developed in future, the pool experiments would need to be repeated in order to determine the maximum number of samples that can be pooled to form a composite sample.

In conclusion, it seems possible to combine two samples of steroids and $\beta$-agonists in a pool, although only for liquid samples, such as urine. When sampling other matrices, such as hair or bristles, it is more difficult to obtain a homogenous mixture, and it is recommended that individual samples be analysed. 


\subsubsection{Identification of emerging risks}

In the case a monitoring programme is fully risk-based, it is possible for emerging risks to be overlooked because the prioritisation of substances is heavily reliant on previous non-compliant findings (see 3.2.2). Emerging risks can be either known risks, which reappear because of changes in the production process or changes to the environment, or unknown risks, which have not previously been detected, in existing chains (EFSA, 2007). In analytical research, it is therefore important for screening to be broad and non-targeted, so that emerging risks can be detected quickly. It is also important to be able to detect emerging risks at an early stage, for example through a holistic approach.

\subsubsection{Screening}

Two types of screening methods can be distinguished: i) screening methods that are designed to test large series of, predominantly negative, samples for a particular parameter (e.g. a substance/group of substances or an effect) quickly (or relatively quickly), and (ii) screening methods that can be used to test a sample for a large/very large number of substances in a single test. Screening methods are qualitative: if screened samples are suspect, they have to be reanalysed using a confirmatory method in order to arrive at definitive conclusions as to the identity and concentration of a component (Figure 15).

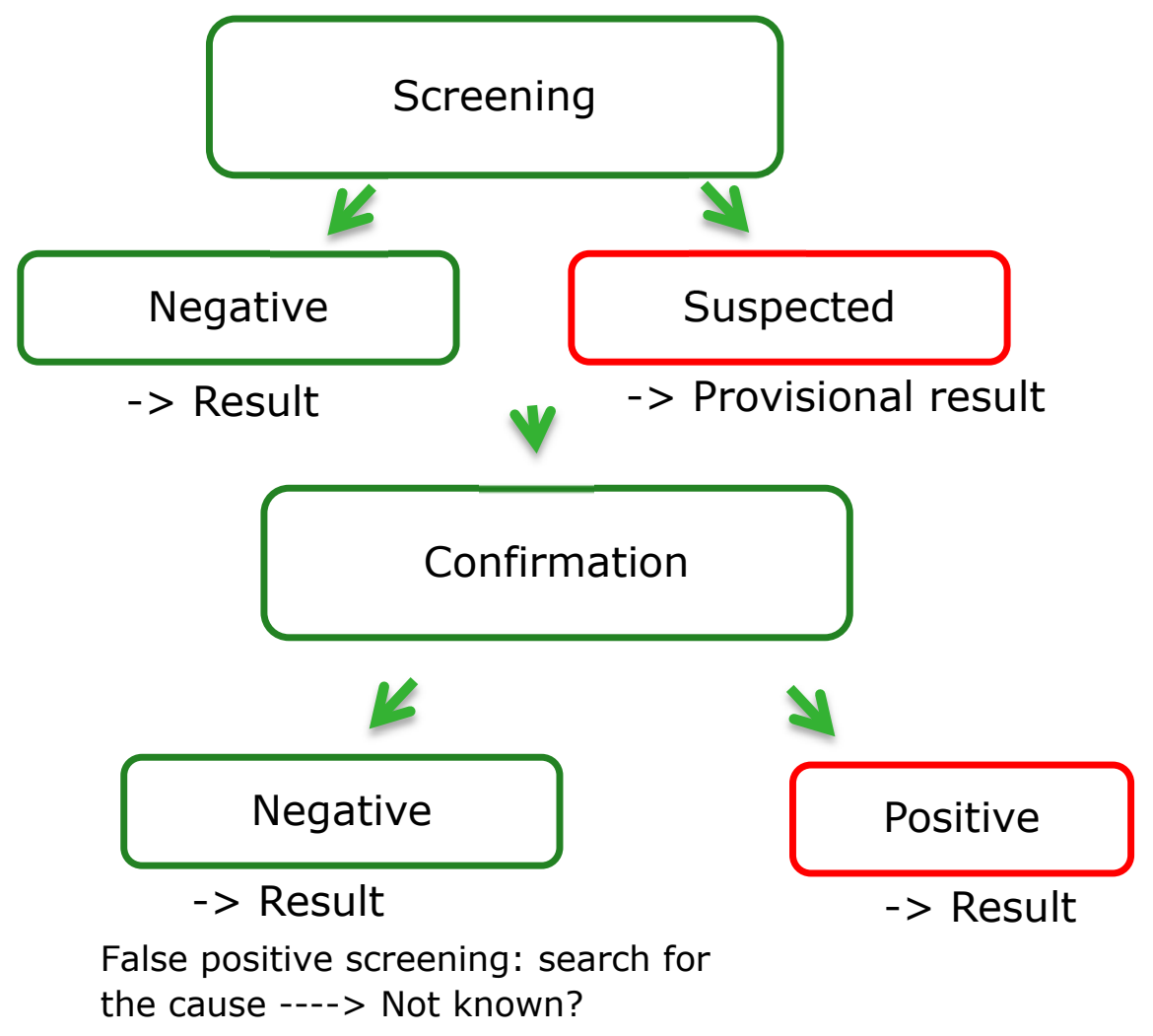

Figure 15 Use of a screening method for detecting chemical substances.

Screening can be done with bioassays and chemical analyses and a distinction can be made between targeted and non-targeted measurements. The two approaches and methods each have their advantages and limitations. The main methods and some of their characteristics are set out in Table 10. 
Table 10 Overview of screening methods.

\begin{tabular}{|c|c|c|}
\hline \multicolumn{3}{|l|}{ Screening methods } \\
\hline & Targeted measurement & Non-targeted measurement \\
\hline \multicolumn{3}{|l|}{ Bioassays } \\
\hline Scope & $\begin{array}{l}\text { 1-10 substances in a single plex/ multi- } \\
\text { plex }\end{array}$ & $\begin{array}{l}\text { All substances that exhibit a certain } \\
\text { bioactivity }\end{array}$ \\
\hline Number per set & ELISA, 96 wells LFD1 & 96 wells $=96 /$ number of replicates \\
\hline $\begin{array}{l}\text { Measuring time per series } \\
\text { (extraction, analysis, data } \\
\text { processing) }\end{array}$ & $\begin{array}{l}\text { ELISA, I day, LFD several minuten-2 } \\
\text { hours }\end{array}$ & $\begin{array}{l}\text { 1-2 days (depending on the necessary } \\
\text { extraction/clean-up and incubation period) }\end{array}$ \\
\hline Sensitivity & Varies & Varies \\
\hline Scope & 1-200 substances with a multi-method & $\begin{array}{l}\text { All substances in the extract that can be } \\
\text { ionised (1000s) }\end{array}$ \\
\hline Number per series & 25 samples & 25 samples \\
\hline $\begin{array}{l}\text { Measuring time per series } \\
\text { (extraction, analysis, data } \\
\text { processing) }\end{array}$ & 2-3 days & 2-3 days \\
\hline Sensitivity & $<0.1-10 \mu \mathrm{g} / \mathrm{kg}$ & $1-100 \mu \mathrm{g} / \mathrm{kg}$ \\
\hline \multicolumn{3}{|c|}{1 LFD: lateral flow device (dipstick). } \\
\hline \multicolumn{3}{|c|}{$\begin{array}{l}2 \text { These techniques can also be used (possibly for the same measurement) as a confirmatory method (identification and quantification), } \\
\text { depending on the method of measurement. }\end{array}$} \\
\hline
\end{tabular}

Screening is currently performed for only a limited number of groups of substances. Most groups are analysed using 'targeted' LC-MS/MS or GC-MS/MS (see Table 3). Table 10 gives an overview of two types of screening methods: bioassays, focused on an effect, and chemical analyses. Both types of screening method may be performed on a targeted or non-targeted basis. A major limitation of targeted methods is that only those components can be detected that are actually being looked for. As these methods are geared to the detection of a predefined set of molecular masses, they are, by definition, unable to detect a new, unknown component with a different mass. In order to remedy this situation, there are basically two possible approaches: effect assays and non-targeted MS (see Table 10).

\subsection{Bioassays}

Bioassays are methods used to detect substances on the basis of 'biorecognition', such as immunological, receptor or other biological interactions. A distinction can be made between structural methods, which detect a given substance/group of substances (targeted), and effect-driven methods used to detect substances that have a specific biological impact (non-targeted).

\section{Structure-orientated bioassays}

These are essentially immuno- and receptor assays. They show the presence of a substance by using antibodies, markers (for example rbST antibodies) or other binder proteins. Detection can take the form of an ELISA or lateral flow ('dip-stick') test, with which a restricted group of structurally closely related substances can be detected. Increasingly, however, so-called multiplex tests are being developed, both in the form of dipsticks with multiple detection channels and automated formats such as Magpix, which can, in theory, be scaled up to 100 different substances and their structural analogues. This assay type is a targeted method because the assay is specifically developed for a substance or a group of substances with closely related structures.

\section{Effect based assays}

Effect based screening assays are methods that detect a biological impact (bioactivity). A well-known and widely used example is the detection of antibiotics (or more precisely: antimicrobial substances) using bacterial growth-inhibition tests. This method is already being deployed in the NP for screening for veterinary antibiotics ('MRL antibiotics') in matrices such as kidneys, meat and eggs. Since this 
method is based on a biological effect, not only veterinary antibiotics but also antibiotics that are not authorised for veterinary use and other substances that inhibit bacterial growth are detected. A limitation of these tests is their sensitivity, which is insufficient to also detect banned antibiotics (group A6) such as chloramphenicol and nitrofurans. Another frequently used effect assay is DR CALUX, an assay based on a modified rat liver cell line for detecting dioxins and dl-PCBs. Hormonal effect assays are also available, based on yeast cells or human cell lines. These allow oestrogenes, androgenes, progesterones and corticosteroids to be identified. The drawback with these methods is that they cannot distinguish between natural and added hormones, which makes them unsuitable for tests on older animals (Nielen et al., 2006; Rijk et al., 2009). Another approach is steroid profiling. Treatment with a steroid produces a measurable change in the overall profile (qualitative and quantitative) of steroids present. Using multivariate analysis, it is possible to detect these changes, in which case the sample is classified as suspect.

The use of effect-based screening has the advantage that, alongside the standard substances, new unknown substances and designer drugs can be detected (Van Ginkel \& Sterk, 2016). They are also deployed for forensic research in areas beyond the scope of the NP (Bovee et al., 2016).

An effect-based screening method is never sufficient in itself, as a suspect result must, in practice, always be followed by a confirmatory method. In order to be successful in detecting new hazards, it is also essential that effective procedures are available in order to identify new 'unknowns' that are detected using these effect-based screening methods.

Effect assays are particularly suitable for detecting group-A substances and screening for antibiotics. In the case of pesticides and mycotoxins, effect screening is more complex, because of the different modes of action involved.

\subsection{Chemical screening methods}

In technical terms, chemical screening methods resemble methods that are also used for quantitative/confirmatory analysis. The difference is that more generic procedures are used for extraction and clean-up. As a result, the methods are less onerous, and more substances are found in the same extract, which means that more substances can be detected at the same time, and at greater speed. A distinction can be made between targeted and non-targeted methods. With targeted methods, only a pre-determined set of substances is measured. With non-targeted methods, a different type of instrument is used and this limitation does not apply, which basically means thousands of substances can be examined in one measurement. Unlike bioassays, MS-based chemical screening methods can be used to simultaneously measure substances with very varied structures and/or biological activities. This makes chemical screening well suited for pesticides and combined screening for different types of residues and contaminants.

\section{Screening using targeted methods}

These are mainly multi-methods based on LC-MS/MS and GC-MS/MS. The instrument usually measures 50-200 substances. There are currently different methods for various kinds of residues and contaminants, i.e. a multi-method for veterinary drugs, another for pesticides, and yet others for mycotoxins or persistent environmental contaminants. In order to measure all of these, several multimethods are thus necessary. The drawback with these methods is that only those substances can be found that are included in the analytical method.

\section{Screening using non-targeted methods}

Non-targeted methods are increasingly being used, thanks especially to the development of LC and GC linked to full-scan high-resolution mass spectrometry (HRMS). These methods are becoming ever more sensitive and user-friendly facilitating its application as screening method.

To some extent, these HRMS methods measure all substances present in the extract: a full sample profile/fingerprint is obtained. The data are then analysed by comparing the exact masses of ions or mass spectra from measurement data with the ions and spectra of reference substances in databases/libraries. If a match is found, it is reported. This system also makes it possible to search a posteriori, enabling a dataset to be tested retrospectively for the presence of components that have 
not been included in previous analyses (Van Ginkel \& Sterk, 2016). It is possible, for example, to determine in which products a given pesticide is particularly prevalent, enabling monitoring to be directed at those products. Retrospective analysis is fairly time-consuming because only individual substances or measurement series can be examined. It is not possible to determine the concentration of a component retrospectively because no reference material or reference standard will have been included in the analysis. Pesticides are currently analysed using non-targeted full-scan HR-MS, although not yet in the NP for Residues. This method needs to be developed for other substances, such as mycotoxins. This is a relatively labour-intensive process, because a database with structural formulas has to be set up and validated. Once the method is applied, pre-processing and analysis take as long as with targeted methods. However, the data analysis takes longer, since all suspicious peaks have to be explored.

A drawback of these broad, non-targeted screening methods is their sensitivity, which is generally not as good as that of targeted analytical methods. It is expected that technical advances will result in, in future, non-targeted methods that will also be sufficiently sensitive. Then, they will eventually replace targeted methods.

\subsection{Conclusions}

Most groups of substances currently measured for NP purposes make use of targeted methods, as described in Table 3. Wherever possible, it is recommended that the samples be broadly screened for the various groups of substances. Effect assays can be used for prohibited substances (group $A$ ), veterinary drugs (B1, B2a, b, d, e) and organochlorinated substances (group B3a), whereas nontargeted screening methods such as HRMS can be used for pesticides (group B2c, B3b) and mycotoxins and ICP-MS for heavy metals (B3c). Broad, non-targeted screening methods can detect emerging hazards that the current targeted methods fail to pick up on. For most groups of substances, the broad screening methods referred to in Table 10 can be used in the NP. This is not possible for a number of substances either because the method does not work at the ML/MRL or because the method cannot distinguish between natural and added substances (e.g. hormones). It can also be the case that the physico-chemical properties of a substance are such that they do not lend themselves to be included in a broad screening method. These substances have to be measured using targeted methods, although analytical methods are becoming increasingly sensitive; hence the expectation that it will eventually be possible to measure all groups of substances using methods for a broad range of substances.

\subsubsection{Holistic approach}

In order to detect emerging risks in time, it is important to focus not only on the measurement of substances, but also to take a holistic approach. New risks may arise from changes in the chain itself or changes in the environment. By identifying the drivers of change and then determining how these factors can be measured using indicators and data sources (Marvin et al., 2009), it is possible to detect new risks on the basis of meta-data. To this end, a very large number of data sources have to be consulted. The use of software tools makes it easier to gather and process information from these sources (EFSA, 2011a). One of the tools that have been much researched is the Europe Media Monitor (EMM); a system developed by the Joint Research Centre of the European Union, which every day automatically gathers and analyses between 80000 and 100000 news articles appearing in traditional and social media the world over (European media monitor). The system comprises three portals: NewsExplorer, NewsBrief and Medisys. NewsExplorer collates news items on the same topics at the end of every day. NewsBrief shows the most popular news articles to have appeared in the last few hours/minutes, grouped by topic. Lastly, Medisys only carries messages on medical topics, grouped per disease. In 2011, Medisys was extended to include the collection and analysis of information on food and feed (Linge \& Belyaeva, 2011). By incorporating smart filters, it is possible to transmit only the relevant hits. Information filters for more than 200 known food risks have been added to the system (Linge \& Belyaeva, 2011). Medisys was adapted by Prins et al. (2012) to search specifically for references to the existence of unauthorised GMOs. This had previously been done manually, which meant that the information found depended on the expert knowledge of the user and that the process was time-consuming. For this reason, an ontological approach was used: an ontology is a dataset comprising different terms (for example: 'Salmonella enteritidis') in a particular research domain in which the relationship between those terms is defined (for example: 'Salmonella enteritidis' belongs to 
the group 'Salmonella spp.') (Gruber, 2009). By defining search terms systematically and hierarchically, it is more likely that all relevant sources of information will be found; adding this ontology to a system such as EMM then automates the collection of information. Ontologies have been used in earlier projects as a means of identifying emerging risks. By way of example, as part of the ERDSS project (2008), a prototype data-analysis system was developed for the salmon supply chain. The system made use of ontologies and inference rules in order to define emerging risks. In addition, research is currently being carried out, as part of the RIKILT 'Big Data' project, into the extent to which information from social media (such as Twitter and Facebook) and internet fora can be used to become acquainted with the illegal use of unauthorised veterinary drugs. Text mining is used to obtain an overview of reports relating to a large number of growth-promoting agents. The findings of this research are currently being used as an input for the NP Working Party and the EURL so that substances can be added to the monitoring programme where appropriate. The structure of the method needs to be adapted in order to provide a comprehensive overview of new growth promoters that are being used.

As already pointed out, the food supply chain is subject to various factors that may cause changes, which can lead to the emergence of new food safety risks. These factors, or 'drivers', could in turn influence each other. In order to understand this relationship, and analyse those factors that most influence the emergence of a new risk, they can be modelled using probability distributions in a probabilistic network, also known as a Bayesian network (BN). This approach was adopted by Marvin et al. (2016) and Bouzembrak and Marvin (2016) to assess the factors affecting international food fraud in Europe. Marvin et al. (2016) linked different types of drivers such as food safety standards in the country of origin and the price of the product in order, among other things, to be able to predict what type of fraud is most likely for a given product. This technique will also be applied in the EFSA's current AQUARIUS project, which involves an analysis of the salmon supply chain. In order to obtain as much information as possible about this chain, a search protocol is being devised for systematic literature review, employing an ontological approach to general vocabulary and BNs in order to link data sources to each other.

\subsection{Conclusions}

The methods described above can be used to detect new risks at an early stage. Text mining and ontologies can be used to detect the use of new illegal agents via social media and internet fora. BNs can be used to link existing databases, thereby enabling the prompt detection of emerging risks. These methods can be seen as complementing the broad screening methods used for detecting emerging risks. 


\section{$4 \quad$ Conclusions and recommendations}

\subsection{Conclusions}

This project examined the extent to which the current NP for Residues can be made more effective and efficient. The red meat supply chain was used as a case study. The use of a decision tree would appear to be the most practical means of achieving a more effective, risk-based implementation of the NP for Residues. As part of this project, three decision trees were designed on the basis of a literature review and expert knowledge for three different groups of chemical hazards: prohibited substances; natural substances and contaminants; and authorised substances. These decision trees can be used to prioritise the current list of substances in the NP for Residues per species with respect to the risks for public health. Political, social or economic considerations were not taken into account.

An initial test run with a subset of substances showed that the decision trees made it possible to categorise substances as having 'high', 'medium' or 'low' priority for monitoring. Although the decision trees were designed for the red meat supply chain, the same methodology can be adopted for other animal products (e.g. white meat and aquaculture products).

To facilitate efficient monitoring, we examined whether it was opportune to combine samples to form a composite sample. It was found that, for certain substances, up to five samples could be combined. However, most groups of substances are analysed using multi-methods, which means that some substances whose detection limit is close to the legal limit will be missed. In the case of liquid samples that are easily homogenised, two samples can be combined to form a composite sample.

In order to be able to detect emerging risks, it is opportune to use broader, non-targeted methods. For NP purposes, the methods most commonly used at present are targeted GC-MS/MS or LC-MS/MS. By using broader, non-targeted methods using effect assays or full-scan HRMS, new substances can be detected and retrospective searches are possible to look for certain substances. Analytical methods are becoming ever more efficient, and it is expected that, in future, it will be possible to analyse nearly all substances using such methods. Furthermore, recent research shows that it is possible to sample other matrices, such as bristles or drops of blood, in order to effectively detect the illegal use of agents.

The illegal use of banned substances can also be detected by searching the internet and social media using text mining. In addition, emerging risks can be detected using a holistic approach with the aid of Bayesian networks.

\subsection{Recommendations}

It is important for a risk-based monitoring programme not to focus exclusively on high-priority substances but also to gear part of the monitoring programme to random sampling in order to detect emerging or new risks and continue to make an accurate estimate of background exposures. The number of samples to be taken at random and how often this random sampling is to be carried out, needs to be decided on a firm statistical basis. A practical option could be to focus on monitoring highpriority substances and screen random samples once or twice a year in order to keep the risk-based monitoring plan under review: Are no substances being missed? Are there any emerging risks, which were not previously being looked for?

For risk based implementation of the NP for Residues, the following steps are recommended:

1. Creation of an expert team for prioritisation of substances in the NP for Residues. This expert team should preferably consist of experts involved in the implementation of the NP and experts with toxicological background. 
2. Compilation of a list of substances that may be found in animal products using data in the literature, monitoring data, RASFF-data and data on use. Inputs could also be obtained from text mining and BNs. In addition to the current list of substances in Directive 96/23/EC, the list could also include dioxins and plant toxins.

3. Determining, for the list of substances, which substances have high, medium or low priority for monitoring for each animal species, using the decision trees in Figures 9 to 11. Consideration may be given to regarding all substances for which non-compliant results have been obtained in the last five years as having high priority and including them in the NP for Residues.

4. A breakdown of the types of animals to be sampled on the basis of the results of step 3 , production and consumption data for the various animal products.

5. Adopting the most appropriate matrix for each group of substances, ensuring that the chance of detection is as high as possible (see Table 6). The results of research into new matrices, such as hair or bristle or drops of blood, should be taken into account in the choice of most effective matrix.

6. Defining a sampling strategy, based on the chosen matrix in step 5 . Kidneys and livers, for example, can only be sampled at the slaughter stage, and feed at the farm stage. Other factors to be taken into account in the selection of animals to be sampled are the production system and/or the age of the animals. Animals are selected for sampling on the basis of 'suspicious' signs, such as injection marks and/or unexpected growth.

7. Discussion of the established list of substances for each animal species and the sampling strategy in the NP Working Party. In addition to the high-prioritised substances in the light of their prevalence and human health risks they entail, other substances may be included in the NP on social or political grounds.

The list of substances and the sampling strategy should be assessed on a yearly basis to decide whether adjustments are necessary. Findings obtained using software tools and statistical analysis as described in 3.3.2.2 can serve as an input. It is also recommended that, wherever possible, comprehensive screening methods be used that not only detect prioritised substances, but also afford a broader perspective, so that emerging risks can be detected. Recommendations from the EU Reference Laboratories can be used in that respect so that harmonised, pan-European methods can be employed.

Another recommendation is to be consistent in storing analytical data so that they can be analysed retrospectively. With this in view, it is important that, by analogy with the EFSA's SSD guidance, that as many (meta-) data on the sample, such as the matrix which was sampled, the LOD/LOQ and the legal limit, is stored as possible.

The advantage of the type of plan described above is that the NP for Residues can be implemented on a risk basis, targeted at those substances that constitute the main risks, per animal species. By following the proposed plan, the NP for Residues can be implemented in a structured and transparent manner, which will make it possible for third parties to evaluate the NP. A drawback with this system is that it is labour-intensive, and a large volume of information is necessary in order to complete the decision trees. Where the necessary information is not fully available, expert knowledge can be used to fill the gaps. This should be documented so that the methodology is transparent and can be followed by others. 


\section{$5 \quad$ Acknowledgements}

The authors wish to thank Gerda van Donkersgoed (RIVM) for providing the consumption data on red meat, and Paulien Adamse for the KAP data on the same. We are also grateful to Martijn Staats (RIKILT) for sharing information obtained as part of his KB Big Data project. We are indebted to Ine van der Fels-Klerx, Marco Blokland, Toine Bovee, Martijn van der Lee, Theo de Rijk, Astrid Rooseboom, Ron Hoogenboom, Hans Mol (RIKILT) and Rianne Hagen (NVWA) for contributing their expert knowledge to this investigation. We are grateful to Waldo De Boer (Biometris) for his calculations on the pooling of samples, Paula Rutgers (RIKILT) for implementing the pool experiments, and Thijs Meijer for the dry blood spot analyses. We wish to thank the RIKILT and NVWA experts who took part in the brainstorming sessions for their contributions to improving the decision trees, the NVWA and the Dutch Ministry of Agriculture, Nature and Food Quality for their financial support for this project, and Marca Schrap (NVWA) for her constructive criticism. 


\section{References}

Becue, I., Bovee, T.F.H., Van Poucke, C., De Groot, M.J., Nielen, M.W.F. \& Van Peteghem, C. (2011). Applicability of a yeast bioassay in the detection of steroid esters in bristles. Analytical and Bioanalytical Chemistry, 399, 1031-1039.

Berendsen, B.J.A., Bor, G., Gerritsen, H.W., Jansen, L.J.M. \& Zuidema, T. (2013). The disposition of oxytetracycline to feathers after poultry treatment. Food Additives \& Contaminants: Part A, 30, 2102-2107.

Bouzembrak, Y. \& Marvin, H.J.P. (2016). Prediction of food fraud type using data from the Rapid Alert System for Food and Feed (RASFF) and Bayesian network modelling. Food Control, 61, 180-187.

Bovee, T.F.H., Mol, H.G.J., Bienenmann-Ploum, M.E., Heskamp, H.H., Van Bruchem, G.D., Van Ginkel, L.A., Kooijman, M., Lasaroms, J.J.P., Van Dam, R. \& Hoogenboom, R.L.A.P. (2016). Dietary supplement for energy and reduced appetite containing the $\beta$-agonist isopropyloctopamine leads to heart problems and hospitalisations. Food Additives \& Contaminants: Part A, 33, 749-759.

CRL (2007). CRL's view on State of the Art Analytical Methods for National Residue Control Plans. Berlin, Bilthoven, Fougières: BVL-CRL, RIVM-CRL, AFSSA-LERMVD-CRL.

Danaher, M., Shanahan, C., Butler, F., Evans, R., O'Sullivan, D., Glynn, D., Camon T., Lawlor, P. \& O'Keefe, M. (2016). Risk-based approach to developing a national residue sampling plan for testing under European regulation for veterinary medicinal products and coccidiostat feed additives in domestic animal production. Food Additives \& Contaminants: Part A, 1-11.

Dop, P. (2016). Nationaal Plan Residuen 2015. Utrecht, Netherlands: NVWA.

Dorne, J.L.C.M., Bordajandi, L.R., Amzal, B., Ferrari, P. \& Verger, P. (2009). Combining analytical techniques, exposure assessment and biological effects for risk assessment of chemicals in food. TrAC Trends in Analytical Chemistry, 28, 695-707.

EFSA (2006). Opinion of the Scientific Panel on Contaminants in the Food Chain on a request from the Commission related to DDT as an undesirable substance in animal feed. EFSA Journal, 433, 1-69.

EFSA (2007). Definition and description of "emerging risks" within the EFSA's mandate. ESAF/SC/415 final. Available at: http://www.efsa.europa.eu/en/home/doc/sc_definition_emerging_risks_en.pdf. Access date: 15/1/2009

EFSA (2011a). Data collection for the identification of emerging risks related to food and feed. EFSA Journal, 9, EN-185. [152 pp.]

EFSA (2011b). Scientific Opinion on Polybrominated Diphenyl Ethers; (PBDEs) in Food EFSA Panel on Contaminants in the Food Chain (CONTAM). EFSA Journal, 9.

EFSA (2012a). Scientific Opinion on the public health hazards to be covered by inspection of meat (swine). EFSA Journal, 20, 2351-2549.

EFSA (2012b). Scientific Opinion on the public health hazards to be covered by inspection of meat (poultry). EFSA Journal, 20, 2741-2920.

EFSA (2013a). Standard Sample Description ver. 2.0. EFSA Journal, 11, 3424.

EFSA (2013b). Guidance on methodological principles and scientific methods to be taken into account when establishing Reference Points for Action (RPAs) for non-allowed pharmacologically active substances present in food of animal origin. EFSA Journal, 11.

EFSA \& EMA (2013). JOINT STATEMENT OF EFSA and EMA on the presence of residues of phenylbutazone in horse meat. EFSA Journal, 11.

EFSA (2016). Report for 2014 on the results from the monitoring of veterinary medicinal product residues and other substances in live animals and animal products.

Gröschl, M. (2008). Current Status of Salivary Hormone Analysis. Clinical Chemistry, 54, 1759-1769.

Gruber, T. (2009). Ontology. In L. Liu \& M.T. Özsu (Eds.), Encyclopedia Database Systems (pp. 1963-1965). US: Springer.

Hanlon, P.R., Hlywka, J.J. \& Scimeca, J.A. (2015). A Risk-Based Strategy for Controlling Chemical Contaminants as Relevant Hazards in Food Ingredients. Food Protection Trends, 35, 99-100.

Havinga, T. \&, van Waarden, F. (2013). Veilig voedsel: Toezicht toevertrauen? Sectorschets toezicht in de voedselsector. The Hague: Scientific Council for Government Policy (WRR). 
Jansen, L.J.M., Bolck, Y.J.C. \& Berendsen, B.J.A. (2016). Feather segmentation to discriminate between different enrofloxacin treatments in order to monitor off-label use in the poultry sector. Analytical and Bioanalytical Chemistry, 408, 495-502.

Linge, J.P. \& Belyaeva, J. (2011). Customisation or MedISys for the monitoring of food and feed hazards.

Marvin, H.J.P., Kleter, G.A., Frewer, L.J., Cope, S., Wentholt, M.T.A. \& Rowe, G. (2009). A working procedure for identifying emerging food safety issues at an early stage: Implications for European and international risk management practices. Food Control, 20, 345-356.

Marvin, H.J.P., Bouzembrak, Y., Janssen, E.M., van der Fels-Klerx, H.J., van Asselt, E.D. \& Kleter, G.A. (2016). A holistic approach to food safety risks: Food fraud as an example. Food Research International.

Nielen, M.W.F., Bovee, T.F.H., Heskamp, H.H., Lasaroms, J.J.P., Sanders, M.B., Van Rhijn, J.A., Groot, M.J. \& Hoogenboom, L.A.P. (2006). Screening for estrogen residues in calf urine: Comparison of a validated yeast estrogen bioassay and gas chromatography-tandem mass spectrometry. Food Additives \& Contaminants, 23, 1123-1131.

NVWA (2015). Risicobeoordeling roodvleesketen - Rund varken, paard, schaap en geit. Utrecht, Netherlands: NVWA.

Patil, G.P. (1995). Editorial: Composite sampling. Environmental and Ecological Statistics, 2, $169-179$.

Poelmans, S., De Wasch, K., Noppe, H., Van Hoof, N., Van Cruchten, S., Le Bizec, B., Deceuninck, Y., Sterk, S., van Rossum, H.J., Hoffmann, M.K. \& De Brabander, H.F. (2005). Endogenous occurrence of some anabolic steroids in swine matrices. Food Additives \& Contaminants, 22, 808-815.

Prins, T.W., Top, J.L., Kok, E.J. \& Marvin, H.J.P. (2012). EMM Ontology on GMOs: customization of MedISys for the monitoring of GMOs without positive safety assessment. Wageningen: RIKILT Wageningen UR [etc.].

Rijk, J.C.W., Bovee, T.F.H., Wang, S., Van Poucke, C., Van Peteghem, C. \& Nielen, M.W.F. (2009). Detection of anabolic steroids in dietary supplements: The added value of an androgen yeast bioassay in parallel with a liquid chromatography-tandem mass spectrometry screening method. Analytica Chimica Acta, 637, 305-314.

SDA (2016a). Antibioticumgebruik bij paarden - Uitkomsten van een survey onder dierenartspraktijken over de jaren 2012 t/m 2014.

SDA (2016b). Het gebruik van antibiotica bij landbouwhuisdieren in 2015 - Trends, benchmarken bedrijven en dierenartsen, en aanpassing benchmarkwaardensystematiek.

van Asselt, E.D., van der Spiegel, M., Noordam, M.Y., Pikkemaat, M.G. \& van der Fels-Klerx, H.J. (2013). Risk ranking of chemical hazards in food - A case study on antibiotics in the Netherlands. Food Research International, 54, 1636-1642.

van Asselt, E.D., Banach, J.L. \& van der Fels-Klerx, H.J. (submitted). Prioritization of chemical hazards in spices and herbs for European monitoring programs.

van der Fels-Klerx, H.J., Van Asselt, E.D., Raley, M., Poulsen, M., Korsgaard, H., Bredsdorff, L., Nauta, M., D'Agostino, M., Coles, D., Marvin, H.J.P. \& Frewer, L.J. (2016). Critical review of methods for risk ranking of food related hazards, based on risks for human health. Critical Reviews in Food Science and Nutrition, 00-00.

van Donkersgoed, G. (2016). Kwaliteitsprogramma Agrarische Producten - Verantwoording 2015. Bilthoven, Netherlands: National Institute for Public Health and the Environment (RIVM).

van Ginkel, L.A. \& Sterk, S.S. (2016). A view on the analytical design of future risk based residue control. Drug Testing and Analysis, 8, 521-524.

van Gorcum, T. (2013). Kwaliteitsprogramma Agrarische Producten - Verantwoording 2013. Bilthoven, Netherlands: National Institute for Public Health and the Environment (RIVM).

van Rhijn, H. \& van der Voorde, S. (2014). Nationaal Plan Residuen 2013. Utrecht, Netherlands: NVWA.

van Rhijn, H. \& van der Voorde, S. (2015). Nationaal Plan Residuen 2014. Utrecht, Netherlands: NVWA.

Van Rossum, C.T.M., Fransen, H.P., Verkaik-Kloosterman, J., Buurma-Rethans, E.J.M. \& Ocké, M.C. (2011). Dutch National Food Consumption Survey 2007-2010. Bilthoven, Netherlands: National Institute for Public Health and the Environment (RIVM).

VRC (2013). Annual report on Surveillance for Veterinary Residues in Food in the UK 2013, Surrey, UK: Veterinary Residues Committee. 
VRC (2015). Matrix Ranking. Available at:

http://webarchive.nationalarchives.gov.uk/20140909095303/http:/vmd.defra.gov.uk/vrc/;

https://www.gov.uk/government/news/closure-of-veterinary-residues-committee-business. Access date: 03-02-2015

WVAB (2015). Richtlijn classificatie van veterinaire antimicrobiële middelen. Houten, Netherlands: KNMvD.

Yulviatun, A. (2016). Risk Ranking of Chemical Hazards in Milk. Wageningen, Netherlands: RIKILT Wageningen UR. 


\section{Annex 1 List of substances in Directive 96/23/EC}

- Group A = Substances having anabolic effect and unauthorized substances

A1 Stilbenes, stilbene derivatives, and their salts and esters

A2 Antithyroid agents

A3 Steroids

A4 Resorcylic acid lactones including zeranol

A5 Bagonists

A6 Compounds included in Table 2 of the Annex to Regulation (EU) 37/2010 ("prohibited substances").

- Group B = Veterinary drugs and contaminants

B1 = Antibacterial substances, including sulphonamides, quinolones

B2 = Other veterinary drugs
a) Anthelmintics
b) Anticoccidials, including nitroimidazoles
c) Carbamates and pyrethroids
d) Sedatives
e) Non-steroidal anti-inflammatory drugs (NSAIDs)
f) Other pharmacologically active substances.

B3 = Other substances and environmental contaminants
a) Organochlorine compounds including PcBs
b) Organophosphorus compounds
c) Chemical elements
d) Mycotoxins
e) Dyes
f) Others. 


\section{Annex 2 Score-based prioritisation}

The semi-quantitative methods described in the literature are based on factors that are relevant for determining risk. These factors are then classified and scores are attributed to each substance so as to arrive at an overall score. The combination of factors and the classification differ according to the method used. Earlier research ascribed priorities to chemical hazards in a number of products on the basis of scores and criteria (Van Asselt et al., 2013). This method, which is based on the risk classification used by the British Veterinary Residue Committee (UK VRC), takes account of the seriousness of the substance and the degree of human exposure, based on exposure of animals, the presence of the substance in products and consumption of the products (VRC, 2013, 2015). A recent project fine-tuned the risk-ranking methodology to take account of the fact that the presence of a substance in products sometimes results from animal exposure to that substance. It is now proposed that the risks posed by substances be ranked, by type of animal, as follows (Yulviatun, 2016):

If historical monitoring data are available in animal products, the risk is calculated as:

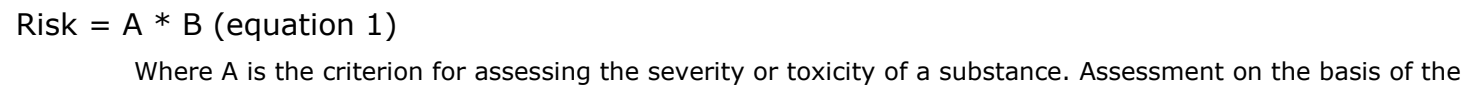

Toxicity is based on data on the acute toxicity, chronic toxicity and carcinogenicity of the substances. The highest score for these three criteria is selected in order to estimate the risk posed by substances in animal products.

In the absence of data on residues in animal products, their prevalence is estimated on the basis of animal exposure. Depending on the substance, animals are exposed via:

- the environment, because of the presence of natural substances and contaminants (group $B_{3}$ ). The risk from this route is not taken into account because of its complexity and the limited volume of available data;

- feed, because of the presence of natural substances and contaminants (group B3)

Risk $=A *(0.25 * C * D)($ equation 2$)$

Where $A$ is the criterion for assessing the severity or toxicity of a substance. The assessment is based on the toxicological reference value (ARfD, ADI/TDI) and/or carcinogenic potential (group assignment of IARC or U.S. EPA), C is the criterion for possible transfer from feed to animal products, based on the percentage of carry-over from feed to animal products $O R$ the concentration ratio between feed and animal products; $D$ is the criterion for prevalence in animal feed. The estimate is based on residue data in products of animal origin (national monitoring data, European monitoring data and RASFF).

- Direct administration (unauthorised substances and veterinary drugs (groups A, B1, \& B2)) Risk $=A *(0.25 * E * F)($ equation 3$)$

Where $A$ is the criterion for assessing the severity or toxicity of a substance. The assessment is based on the toxicological reference value (ARfD, ADI/TDI) and/or carcinogenic potential (group assignment of IARC or U.S. EPA); E is the criterion for the use of veterinary drugs, based on DDDA/year as obtained from SDA-reports; $F$ is the criterion for possible carry-over to animal products, based on the withdrawal period for veterinary drugs.

In order to estimate the prevalence, via feed or direct administration to the animal, two criteria are applied in both cases ( $C$ and $D$ for feed and $E$ and $F$ for direct administration). In order to ensure that prevalence via these indirect routes is given equal weight to prevalence via animal products when determining the final risk, these factors were multiplied by 0.25 . The classification of the scores for the various criteria is based on a number of scientific publications (Danaher et al., 2016; Hanlon, Hlywka, \& Scimeca, 2015; Van Asselt et al., 2013; Van Asselt, Banach, Van der Fels-Klerx, submitted; VRC, 2015). By way of example, the following table sets out the criteria for toxicity (factor A). 


\begin{tabular}{|c|c|c|c|c|}
\hline \multirow[t]{2}{*}{ Criteria } & \multicolumn{4}{|l|}{ Score } \\
\hline & 1 & 2 & 3 & 4 \\
\hline \multicolumn{5}{|l|}{$\begin{array}{l}\text { A: Criterion for toxicity, } \\
\text { based on: }\end{array}$} \\
\hline $\begin{array}{l}\text { Acute Reference Dose } \\
(\text { ARfD })(\mu \mathrm{g} / \mathrm{kg} \text { bw/day) }\end{array}$ & $\geq 200$ & $\geq 50-<200$ & $\geq 10-<50$ & $<10$ \\
\hline OR carcinogenicity & $\begin{array}{l}\text { Not classified as } \\
\text { carcinogenic to } \\
\text { humans (IARC group } 3 \\
\text { or USEPA Group D), } \\
\text { OR probably not } \\
\text { carcinogenic to } \\
\text { humans (IARC Group } 4 \\
\text { or US EPA Group E) }\end{array}$ & $\begin{array}{l}\text { Possibly carcinogenic } \\
\text { (IARC Group 2B or US } \\
\text { EPA Group C) }\end{array}$ & $\begin{array}{l}\text { Probably carcinogenic } \\
\text { (IARC Group 2A or US } \\
\text { EPA Group B1 and B2) } \\
\text { OR insufficient } \\
\text { information to classify } \\
\text { the substance }\end{array}$ & $\begin{array}{l}\text { Carcinogenic to } \\
\text { humans (IARC Group } 1 \\
\text { or US EPA Group A) }\end{array}$ \\
\hline
\end{tabular}

In addition to the toxicity of substances and their prevalence in animal products, it is important to take human exposure into account when determining the risk posed by substances. To this end, consumption data can be used which, by way of analogy to the table above, are given a score of between 1 (low exposure) and 4 (high exposure). An earlier study used the following classification (Van Asselt et al., 2013):

Score 1: $\leq 10 \mathrm{~g}$ of product/day

Score 2: $>10-\leq 50 \mathrm{~g}$ of product/day

Score 3: $>50-\leq 100 \mathrm{~g}$ of product/day

Score 4: $>100 \mathrm{~g}$ of product/day.

These scores are then multiplied by equation 1 to 3 in order to arrive at an overall assessment of the risk. Where several criteria are taken into account for the purpose of determining risk, Multi-Criteria Decision Analysis (MCDA) can be used. In this method, various criteria are multiplied together to determine the risk. A weighting may be attributed to each of the criteria on the basis of input from stakeholders. In equations 2 and 3, we attached a weighting of 0.25 to prevalence via indirect routes so as to give the total prevalence of a substance the same weight as its toxicity. If stakeholders consider certain criteria to be more important, their weighting can be increased. 


\section{Annex 3 Pool experiments}

\section{Materials:}

Cattle urine:

- Urine 1: blank urine sample of cow no 1

- Urine 2: blank urine sample of cow no 2

- Urine 3: blank urine sample of cow no 3

- Urine 4: blank urine sample of cow no 4

- Urine 5: blank urine sample of cow no 5

$\beta$-agonists:

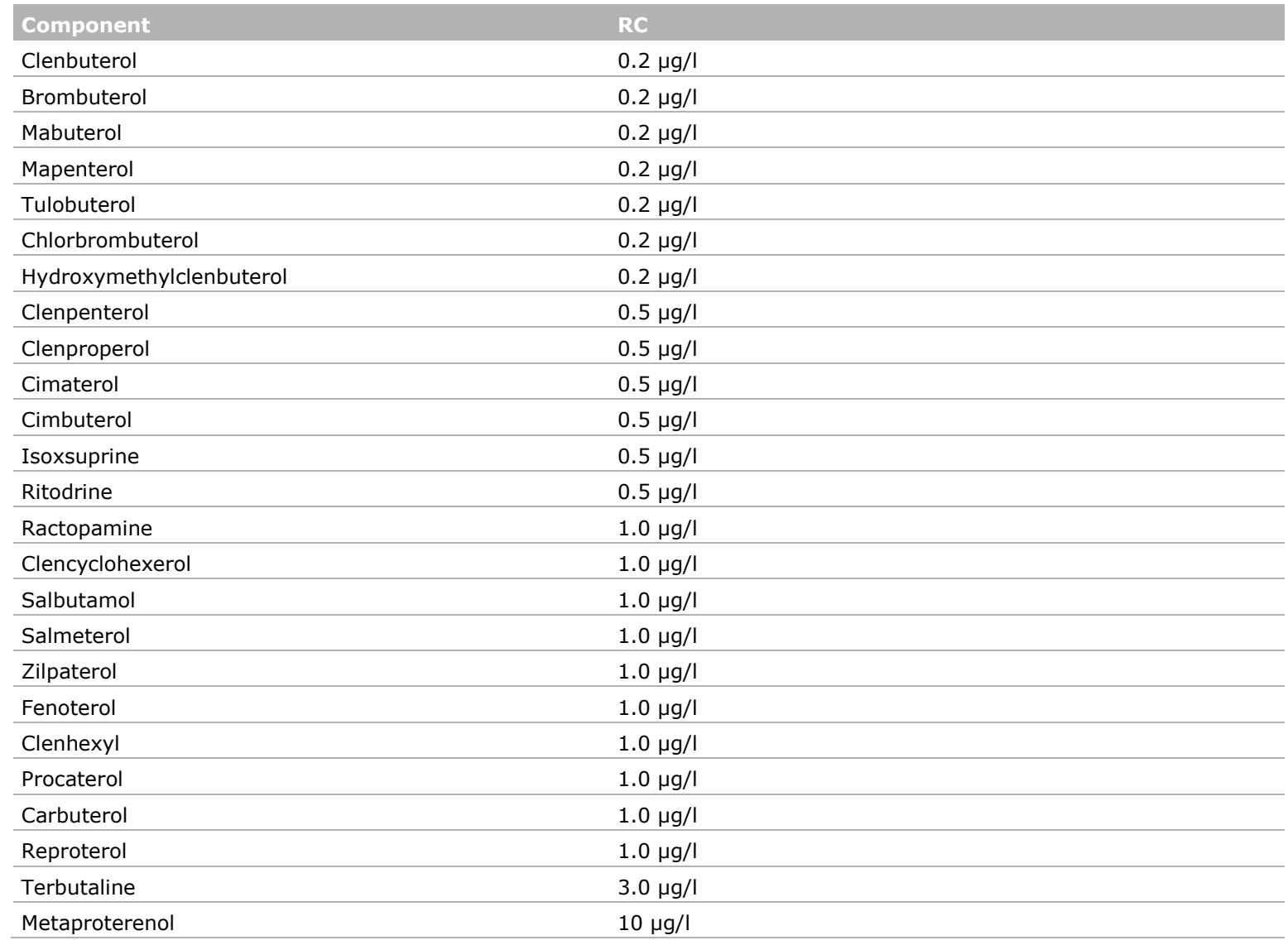

\section{Experiment 1: Pool experiments with 1 urine sample}

Solution 1: Urine 1 enriched with $\beta$-agonists up to RC

Dilute as follows:

\begin{tabular}{ll} 
Number & Dilution \\
\hline 1 & Undiluted (solution 1 ) \\
\hline 2 & Dilute $2 x: 1 x$ solution $1+1$ x urine 1 \\
\hline 3 & Dilute $3 x: 1 x$ solution $1+2 x$ urine 1 \\
\hline 4 & Dilute $4 x: 1 x$ solution $1+3 x$ urine 1 \\
\hline 5 & Dilute $5 x: 1 x$ solution $1+4 x$ urine 1 \\
\hline
\end{tabular}


Solution 2: Urine 1 enriched with $\beta$-agonists up to $2 \times R C$

Dilute as follows:

\begin{tabular}{ll} 
Number & Dilution \\
\hline 6 & Undiluted (solution 2$)$ \\
\hline 7 & Dilute $\times 2: 1 \times$ solution $2+1 \times$ urine 1 \\
\hline 8 & Dilute $\times 3: 1 \times$ solution $2+2 \times$ urine 1 \\
\hline 9 & Dilute $\times 4: 1 \times$ solution $2+3 \times$ urine 1 \\
\hline 10 & Dilute $\times 5: 1 \times$ solution $2+4 \times$ urine 1 \\
\hline
\end{tabular}

Solution 3: Urine 1 enriched with $\beta$-agonists up to $3 \times R C$

Dilute as follows:

\begin{tabular}{ll} 
Number & Dilution \\
\hline 11 & Undiluted (solution 3$)$ \\
\hline 12 & Dilute $x 2: 1 \times$ solution $3+1 \times$ urine 1 \\
\hline 13 & Dilute $\times 3: 1 \times$ solution $3+2 x$ urine 1 \\
\hline 14 & Dilute $x 4: 1 \times$ solution $3+3 \times$ urine 1 \\
\hline 15 & Dilute $\times 5: 1 \times$ solution $3+4 x$ urine 1 \\
\hline
\end{tabular}

\section{Experiment 2: Pool experiment with multiple urine samples}

Solution 1: Urine 1 enriched with $\beta$-agonists up to RC

Dilute as follows:

\begin{tabular}{ll} 
Number & Dilution \\
\hline 16 & Undiluted (solution 1 ) \\
\hline 17 & Dilute $\times 2: 1 \times$ solution $1+1 \times$ urine 2 \\
\hline 18 & Dilute $\times 3: 1 \times$ solution $1+1 \times$ urine $2+1 \times$ urine 3 \\
\hline 19 & Dilute $\times 4: 1 \times$ solution $1+1 \times$ urine $2+1 \times$ urine $3+1 \times$ urine 4 \\
\hline 20 & Dilute $\times 5: 1 \times$ solution $1+1 \times$ urine $2+1 \times$ urine $3+1 \times$ urine $4+1 \times$ urine 5 \\
\hline
\end{tabular}

Solution 2: Urine 1 enriched with $\beta$-agonists up to $2 \times R C$

Dilute as follows:

\begin{tabular}{ll} 
Number & Dilution \\
\hline 21 & Undiluted (solution 2 ) \\
\hline 22 & Dilute $\times 2: 1 \times$ solution $2+1 \times$ urine 2 \\
\hline 23 & Dilute $\times 3: 1 \times$ solution $2+1 \times$ urine $2+1 \times$ urine 3 \\
\hline 24 & Dilute $x 4: 1 \times$ solution $2+1 \times$ urine $2+1 \times$ urine $3+1 \times$ urine 4 \\
\hline 25 & Dilute $\times 5: 1 \times$ solution $2+1 \times$ urine $2+1 \times$ urine $3+1 \times 4+1 \times$ urine 5 \\
\hline
\end{tabular}

Solution 3: Urine 1 enriched with $\beta$-agonists up to $3 \times R C$

Dilute as follows:

\begin{tabular}{ll} 
Number & Dilution \\
\hline 26 & Undiluted (solution 3$)$ \\
\hline 27 & Dilute $x 2: 1 \times$ solution $3+1 \times$ urine 2 \\
\hline 28 & Dilute $\times 3: 1 \times$ solution $3+1 \times$ urine $2+1 \times$ urine 3 \\
\hline 29 & Dilute $\times 4: 1 \times$ solution $3+1 \times$ urine $2+1 \times$ urine $3+1 \times$ urine 4 \\
\hline 30 & Dilute $\times 5: 1 \times$ solution $3+1 \times$ urine $2+1 \times$ urine $3+1 \times$ urine $4+1 \times$ urine 5 \\
\hline
\end{tabular}

\section{Analyses}

The experiments described above were carried out in duplicate. All solutions indicated above and the five blank samples were analysed in accordance with RIKILT SOP A967. 
RIKILT Wageningen University \& Research P.O. Box 230

6700 AE Wageningen

The Netherlands

$\mathrm{T}+31(0) 317480256$

www.wur.eu/rikilt

RIKILT report 2018.003
The mission of Wageningen University \& Research is "To explore the potential of nature to improve the quality of life". Under the banner Wageningen University \& Research, Wageningen University and the specialised research institutes of the Wageningen Research Foundation have joined forces in contributing to finding solutions to important questions in the domain of healthy food and living environment. With its roughly 30 branches, 5,000 employees and 10,000 students, Wageningen University \& Research is one of the leading organisations in its domain. The unique Wageningen approach lies in its integrated approach to issues and the collaboration between different disciplines.

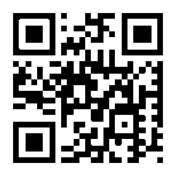





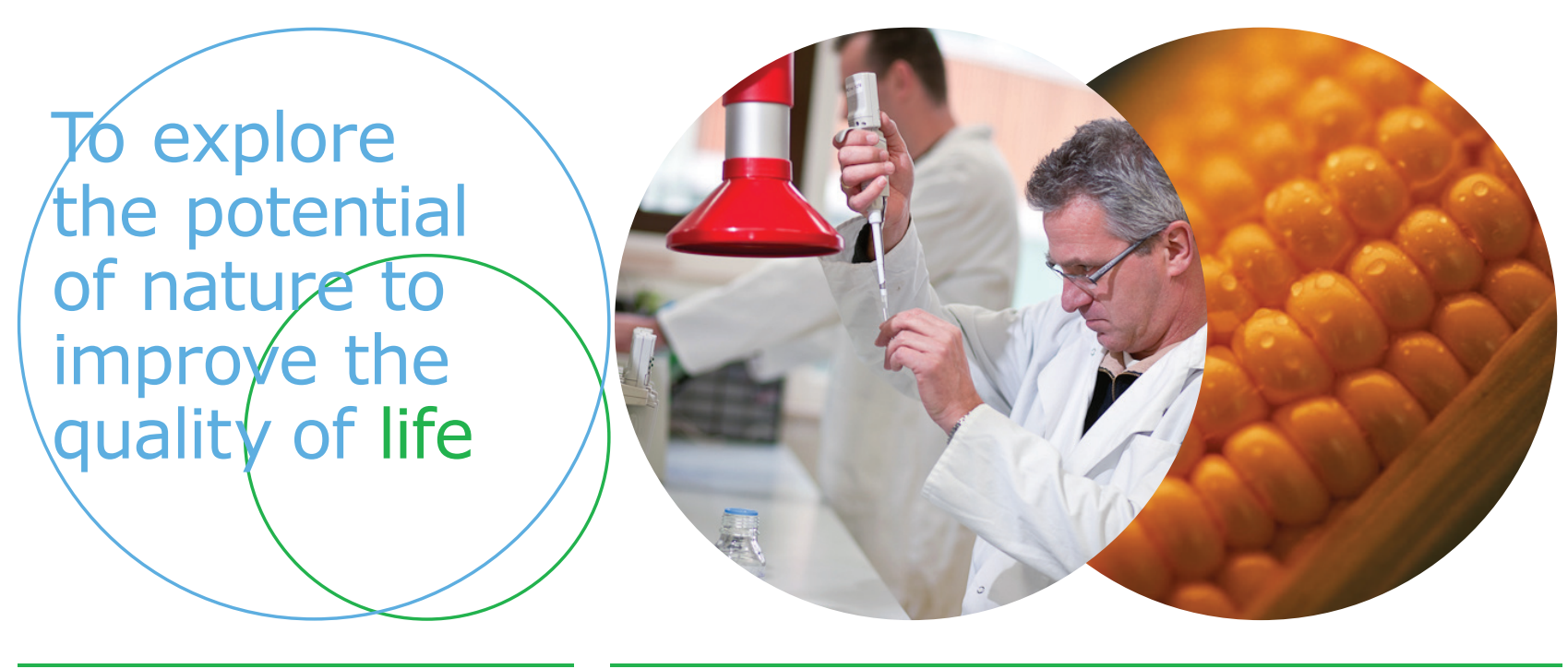

RIKILT Wageningen University \& Research P.O. Box 230

6700 AE Wageningen

The Netherlands

T +31 (0)317480256

www.wur.eu/rikilt

Report 2018.003
The mission of Wageningen University \& Research is "To explore the potential of nature to improve the quality of life". Under the banner Wageningen University \& Research, Wageningen University and the specialised research institutes of the Wageningen Research Foundation have joined forces in contributing to inding solutions to important questions in the domain of healthy food and living environment. With its roughly 30 branches, 5,000 employees and 10,000 students, Wageningen University \& Research is one of the leading organisations in its domain. The unique Wageningen approach lies in its integrated approach to issues and the collaboration between different disciplines. 